\title{
Novel Concept in Pulmonary Delivery
}

\author{
Maria Carafa ${ }^{1}$, Carlotta Marianecci ${ }^{1}$, \\ Paolino Donatella², Luisa Di Marzio3, \\ Christian Celia ${ }^{4}$, Massimo Fresta ${ }^{4}$ and Franco Alhaique ${ }^{1}$ \\ ${ }^{1}$ Department of Drug Chemistry and Technologies, \\ "Sapienza", University of Rome, Rome \\ ${ }^{2}$ Department of Experimental and Clinical Medicine, \\ Faculty of Medicine, University "Magna Graecia" Catanzaro \\ ${ }^{3}$ Department of Drug Science, \\ University of Chieti "G. D'Annunzio", Chieti \\ ${ }^{4}$ Department of Pharmacobiological Sciences, \\ Faculty of Pharmacy, University "Magna Graecia" Catanzaro
}

\section{Introduction}

This chapter deals with recent advances in the nanovector approach to the pulmonary delivery of therapeutic substances; it also describes briefly the physiology of the lungs and the main factors affecting pulmonary delivery (Figure 1).

The development of an innovative nanocarrier, able to deliver the drug to the desired site of action, is highly dependent on the nature of the active substance and on its desired mode of action.

A delivery technology can thus be used to:

- $\quad$ reduce systemic exposure and improve drug targeting;

- circumvent the parenteral route or reduce the number of injections;

- achieve sustained plasma levels of the drug;

- $\quad$ reduce side - effects;

- modulate the effect of the drug, specifically in the case of vaccines, where the delivery system can modify the ratio of humoral and cellular response;

- $\quad$ increase patient compliance;

- $\quad$ reduce the price of the therapy;

- increase patent life and/or circumvent patents of competitors.

Numerous approaches involving non - parenteral routes, such as intestinal, nasal, buccal, transdermal and rectal, have been examined, but most of them are inadequate for a satisfactory therapeutic response. On the other hand, the pulmonary route represents a great promise for the systemic delivery and bioavailability of peptides and proteins, since lungs are highly permeable and accessible by normal inhalation methods. Actually, the pulmonary 


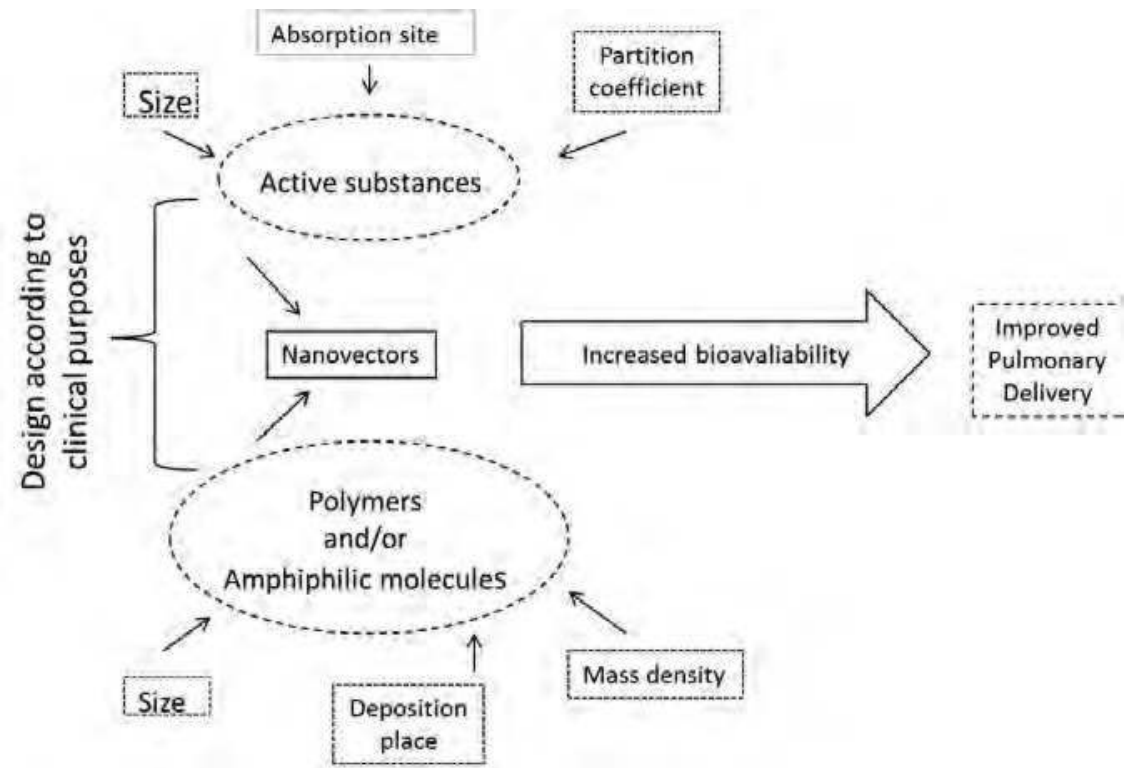

Fig. 1. Factors affecting pulmonary delivery

route typically shows from 10 to 200 times greater bioavailability with respect to other non invasive routes (Patton \& Byron, 2007 ). Thus, various pharmaceutical techniques have been introduced to take advantage of this route. These include formulations using specific and innovative excipients, chemical modifications of drugs, polymeric and/or amphiphilic Drug Delivery Systems (DDSs), particle engineering, inhalation devices.

In particular, over the past decade, the use of DDSs involving micro or nanocarriers and particle engineering techniques were remarkably developed and the resulting pharmaceutical techniques have been eagerly applied to the pulmonary delivery of drugs.

Inhalation is also a proven means of systemic delivery for drugs that have limited bioavailability by other routes or would benefit from rapid onset of action and a variety of products are being developed for this purpose (Gonda, 2006; Patton \& Byron, 2007 ).

At the same time, in recent decades, advances in device design and formulation science have addressed the need for more efficient inhalers that are capable of delivering larger doses to the lung with low extrathoracic deposition. Once deposited in the lungs, drug disposition (dissolution, absorption, distribution, metabolism and elimination) and the influence of pulmonary pharmacokinetics (PK) are the critical determinants of clinical outcomes in terms of drug efficacy and safety. Pulmonary disposition remains poorly understood despite modern capabilities in imaging, analytical and biological science which make measurement of drug disposition and mode of action more accessible. For these reasons the development of new inhaled medicines capable to allow improvements in current therapy is a promising challenge in the development new DDSs.

A number of benefits result from inhalation of drugs and a continuously increasing number of inhaled drugs and nanomedicines are becoming available for the treatment various 
diseases. Inhalation of drugs is convenient and extremely efficient to treat diseased airways. It allows a targeted therapy with high drug concentrations in the tissue of interest and low systemic drug exposure (and thereby reduced side effects). Inhalation aerosols have also been developed for systemic drug administration. The large absorptive surface area, the very thin diffusion path to the bloodstream and the elevated blood flow make the lung a port of entry to the systemic circulation and proteins are absorbed more efficiently from the lungs than from any other non-invasive route of drug administration.

Only one inhaled therapeutic protein is currently available on the market. It is recombinant human deoxyribonuclease I (Dornase alfa) indicated for the treatment of cystic fibrosis (CF) and marketed since 1994.

Recombinant human deoxyribonuclease I is a glycoprotein of $37 \mathrm{kDa}$, which selectively cleaves DNA. In CF patients, retention of viscous purulent secretions in the airways contributes both to reduced pulmonary function and to exacerbation of infection. Purulent pulmonary secretions contain very high concentrations of extracellular DNA released by degenerating leukocytes. Dornase alfa is delivered to CF patients by inhalation of an aerosol mist produced by a pneumatic nebulizer. It hydrolyses the DNA in airway secretions and reduces their viscoelasticity.

Inhalation can represent the most favourable non-invasive route of administration for insulin $(5.8 \mathrm{kDa})$ because insulin bioavailability can reach $37 \%$ following inhalation while it reaches at most $1 \%$ following oral, sublingual, nasal or transdermal administration without chemical enhancers (Cefalu, 2004; Illum, 2002). The first inhaled insulin product, Exubera ${ }^{\circledR}$, was approved in January 2006 but withdrawn from the market already in October 2007 due to disappointing sales.

Another inhaled insulin product, AFREZZATM, is currently under review by the FDA for the treatment of type 1 and type 2 diabetes (Neumiller \& Campbell 2010; Rossiter et al., 2010).

AFREZZA $^{\mathrm{TM}}$ is an ultra rapid acting insulin comprising Technosphere ${ }^{\circledR}$ insulin powder in unit dose cartridges for administration with the inhaler. The Technosphere ${ }^{\circledR}$ powder formulation is prepared by precipitating insulin from solution onto preformed diketopiperazine particles, which readily dissolve once in the lung environment. AFREZZA ${ }^{\mathrm{TM}}$ appears to overcome several limitations of Exubera ${ }^{\circledR}$. Technosphere ${ }^{\circledR}$ insulin is both rapidly absorbed and eliminated and its pharmacokinetic profile mimics more closely normal physiologic insulin release than injection of regular human insulin as well as of rapid-acting analogues.

A few small-scale clinical trials have been conducted on inhalation of other systemicallyacting therapeutic proteins, including interferon alpha-2b $(19.3 \mathrm{kDa})$, human growth hormone (22 kDa) (Walvoord et al., 2009), an erythropoietin-Fc fusion protein (112 kDa) (Dumont et al., 2005). Inhalation of growth hormone is a potential alternative to growth hormone injection, which could offer improved patient adherence especially in pediatric patients. The bioavailability of inhaled growth hormone was 3.5\% relative to subcutaneous injection in children, while it reached $7.6 \%$ in adults (Walvoord et al., 2009). The hypothesis behind this difference is that children have smaller oropharynx and larynx, which results in different deposition patterns as compared to adults. Although children preferred the inhalation route of therapy, ongoing development of growth hormone inhalation has been delayed due to its low bioavailability. An erythropoietin-Fc fusion protein was absorbed in 
the bloodstream following delivery to the central lung regions in humans, with a dosedependent concentrations in the serum, suggesting that large therapeutic molecules can be delivered to humans via the lungs using the FcRn-mediated transport pathway (Dumont et al., 2005).

\section{Practical issues in the pulmonary delivery}

\subsection{Physiological features of the lungs}

The lung resembles an inverted tree, where the trachea or trunk subdivides into two main bronchi and these latter successively branch into more and more narrow and short bronchioles. In total, the trachea undergoes 23 bifurcations before it reaches the alveolar sacs. The first 16 generations compose the conducting region where air is filtered, warmed, humidified and conducted to the respiratory region. Gas exchange between airspaces and blood capillaries occurs in the respiratory region, which includes the respiratory bronchioles, the alveolar ducts and the alveolar sacs.

Two different epithelia line the conducting and respiratory regions. A pseudo stratified columnar epithelium lines the proximal conducting airways and is composed of ciliated columnar cells, goblet or mucus secreting cells and basal or progenitor cells (Parkes, 1994). It is progressively replaced by a simple cuboidal cell layer in the more distal airways and by a very thin epithelial lining in the alveoli. Squamous type I pneumocytes cover $95 \%$ of the alveolar surface, owing to their large apical surface and thinness $(0.05 \mu \mathrm{m})$. Cuboidal type II pneumocytes produce the lung surfactant and are progenitor for type I cells. Type II pneumocytes are located in the corners of the alveoli. The surface area of the alveolar epithelium reaches $100 \mathrm{~m}^{2}$, which is enormous as compared to the $0.25 \mathrm{~m}^{2}$ surface area of the airways (Crapo et al.,1982; Mercer et al., 1994).

Mucociliary clearance is one of the most important defense mechanisms to eliminate dust and microorganisms in the lungs (Van der Schans, 2007).

The mucus is produced by goblet cells and sub-mucosa glands. It covers the entire airway surface and its thickness ranges from $5 \mu \mathrm{m}$ to $55 \mu \mathrm{m}$ (Clunes \& Boucher, 2007; Lai et al., 2009). It consists of an upper gel phase made of $95 \%$ water, $2 \%$ mucin, a highly glycosylated and entangled polymer, as well as salts, proteins and lipids (Bansil \& Turner, 2006). A periciliary liquid layer underlies the mucus gel and its low viscosity allows effective cilia beating. The mucus is transported by the coordinated beating of the cilia and by expiratory airflow towards the oropharynx at an average flow rate of $5 \mathrm{~mm}$ per minute. Mucus, cells and debris coming from the nasal cavities and from the lung meet in the pharynx, are mixed with saliva and are swallowed.

Pulmonary surfactant is responsible for biophysical stabilizing activities and innate defense mechanisms. It lines the alveolar epithelial surfaces and overflows into the conductive airways so that the surfactant film is continuous between alveoli and central airways (Bernhard et al., 2004). Pulmonary surfactant is composed of $80 \%$ phospholipids (half of which being dipalmitoylphosphatidylcholine), 5-10\% neutral lipids (mainly cholesterol), 5$6 \%$ specific surfactant proteins and 3-4\% non-specific proteins (Perez-Gil, 2008).

The phospholipids are mainly responsible for forming the surface active film at the respiratory air-liquid interface. In water, phospholipids self-organize in the form of bilayers. 
Bilayers are also the structural form in which surfactant is assembled and stored by pneumocytes in lamellar bodies. At the air-liquid interface, phospholipids form oriented monolayers, with the hydrophilic headgroups oriented towards the aqueous phase and the hydrophobic acyl chains pointing towards the air. The higher the concentration of phopholipid molecules at the interface, the lower the surface tension, the lower the energy required to enlarge the alveolar surface during inspiration.

Specific surfactant proteins include SP-A, SP-B, SP-C and SP-D. SP-A and SP-D are hydrophilic while SP-B and SP-C are hydrophobic. SP-A is able to bind multiple ligands, including sugars, $\mathrm{Ca}^{2+}$ and phospholipids. This property allows SP-A to bind to the surface of pathogens, contributing to their elimination from the airways. Recognition of SP-A by specific receptors on alveolar macrophages stimulates phagocytosis of the pathogens. SP-B is strictly required for the biogenesis of pulmonary surfactant and its packing into lamellar bodies. Both, SP-B and SP-C promote rapid transfer of phospholipids from bilayers stores into air- liquid interfaces.

Luminal airway and alveolar macrophages are at the forefront of lung defence and their primary role is to participate in innate immune responses, that is, chemotaxis, phagocytosis, and microbial killing (Geiser, 2010). They also downregulate adaptive immune responses and protect the lung from T-cell-mediated inflammation (Holt et al., 2008). Macrophages are tightly applied on the surface of respiratory epithelia. They are immersed in the lung lining fluid beneath the surfactant film.

Although they occupy only $1 \%$ of the alveolar surface, they are capable to clean particles from the entire alveolar surface due to amoeboid movements (Geiser, 2010). In contrast to surface macrophages, interstitial macrophages are primarily involved in adaptive immunity by interfacing with lymphocytes via antigen presentation and production of cytokines (Geiser, 2010).

The lung presents a lower level of metabolism than the gastrointestinal tract and liver. Yet, various peptidases are distributed on the surface of different cell types in the lung, including bronchial and alveolar epithelial cells, submucosal glands, smooth muscles, endothelial cells, connective tissue. Proteases are largely present in lysosomes (Buhling et al., 2004). Proteases that degrade the extracellular matrix are secreted by different structural cells or are membrane bound (Stamenkovic, 2003).

Proteases play an essential role in cell and tissue growth, differentiation, repair, remodelling, cell migration and peptide-mediated inflammation (van der Velden \& Hulsmann, 1999). Proteases can also be released in the airspaces by activated macrophages and neutrophils in case of inflammatory reactions in the respiratory tract (Buhling et al., 2006; Tetley, 2002). Blood supply to the lungs is divided among the pulmonary and systemic circulations (Altiere \& Thompson, 1996). The pulmonary circulation consists of the pulmonary artery that leaves the right heart, branches into a dense pulmonary capillary bed that surrounds the alveoli and finally coalesces into the pulmonary vein that drains into the left heart. One hundred percent of the cardiac output flows through the pulmonary circulation. Its principal functions are gas exchange with air in the alveoli and nutrients supply to terminal respiratory units. The lungs receive a second blood supply via the systemic circulation, commonly referred to as the bronchial circulation. The bronchial circulation originates from the aorta and provides oxygenated blood and nutrients to all 
structures of the tracheobronchial tree. Lymphatic vessels exist in close proximity of major blood vessels and of the airways (El-Chemaly et al., 2009). The lungs have unique physiological features and provide many conditions that favour the absorption of peptides and proteins.

\subsection{Barriers to the pulmonary delivery of active substances}

\subsubsection{Deposition of nanocarriers through the respiratory tract}

As pointed out in the section on lung physiology, the structure of the lung tissue largely varies according to airway generation and the fate of nanomedicines will similarly vary depending on the structures on which they deposit. The site of deposition of an inhaled formulation within the respiratory tract depends on the aerodynamic diameter of the aerosol particles. The aerodynamic diameter of a particle, $\mathrm{d}_{\mathrm{aer}}$, is equivalent to the diameter of a unit density $\left(\rho_{0}\right)$ sphere that has the same terminal velocity in still air as the particle:

$$
d_{\text {aer }}=d \sqrt{\frac{\rho}{\rho_{0} X}}
$$

where $\mathrm{d}$ is the geometric diameter of the particle, $\rho$ is the particle density and $\chi$ is the particle dynamic shape factor denoting deviation of shape from sphericity (Hinds, 1999).

Filtering of large particles $\left(\mathrm{d}_{\mathrm{aer}}>5 \mu \mathrm{m}\right)$ occurs in upper airways (mouth, trachea and main bronchi) by inertial impaction. One to $5 \mu \mathrm{m} \mathrm{d}$ aer particles deposit by gravitational settling in the central and distal tract. Particles with $d_{a e r}<1 \mu \mathrm{m}$ remain suspended in the air and are mostly exhaled. Ultrafine particles $(<100 \mathrm{~nm})$ can largely deposit in the respiratory tract by random Brownian motion: particles $<100 \mathrm{~nm}$ reach the alveolar region while particles $<10$ $\mathrm{nm}$ already deposit in the tracheo-bronchial region due to their high diffusion coefficients (Heyder at al., 1986).

Drug delivery inhalers, that include nebulizers, metered-dose inhalers and dry powder inhalers, generate particles with a $\mathrm{d}_{\mathrm{aer}}$ in the micron-size range for deposition in the tracheobronchial tree $(3-10 \mu \mathrm{m})$ in order to treat the airways (e.g., $\beta 2$ mimetics) or in the alveolar region $(1-3 \mu \mathrm{m})$ for systemic drug absorption (e.g., insulin) (Figure 2).

Therapeutic proteins can be delivered to the lungs by any medical inhaler. Yet, medical inhalers are not designed to produce ultrafine particles. Ultrafines require enormous energy for their creation, that is, for the atomization of the solution into nano-sized liquid droplets or for the complete de-agglomeration of nanosized dry powder particles. Therefore, drug formulations based on nanoparticles are most often delivered to the respiratory tract by nebulization of colloidal suspensions (Dailey et al., 2003). Developments of the preparation of dry powder microparticles as nanoparticles carriers for pulmonary drug delivery were also reported quite recently (Tsapis et al., 2002). It should be noted, ultrafines are generated in abundance in our environment by the most significant pollution sources, which are those related to combustion processes (Morawska et al., 2005). Epidemiologic studies have provided evidence that an increase in atmospheric ultrafines is associated with adverse pulmonary and cardiovascular effects in susceptible parts of the population. Therefore, significant research has focused on the fate of inhaled ultrafines in the body and ultrafines have been frequently produced in laboratories using spark generators (Geiser et al., 2008). 


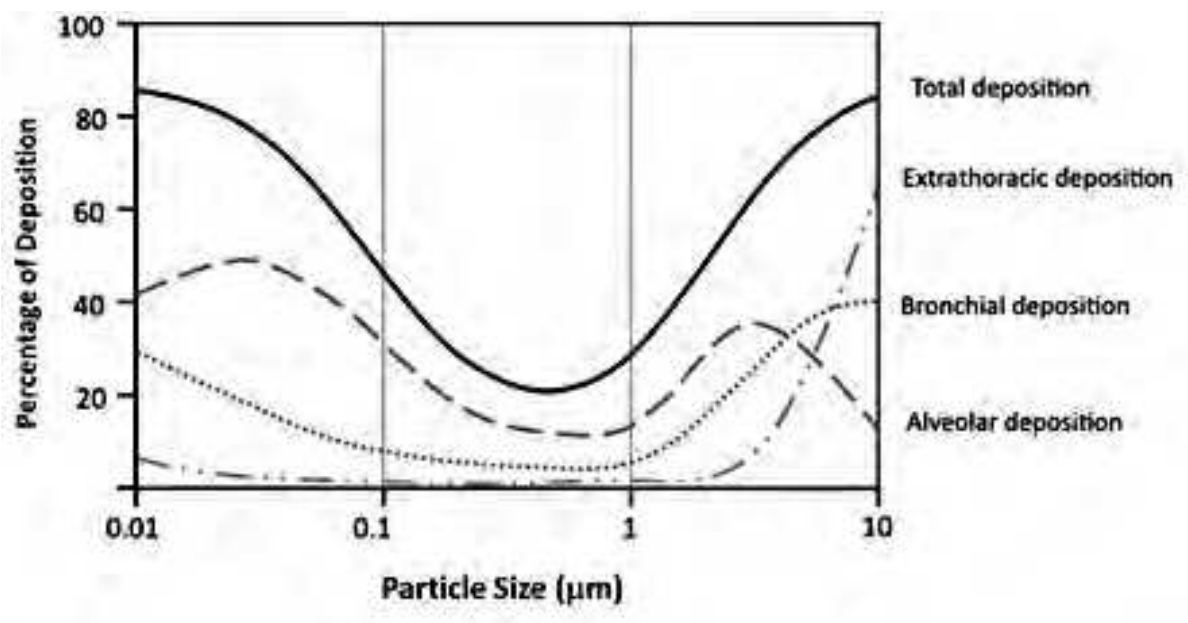

Fig. 2. Deposition of nanocarriers in human respiratory tract as a function of size

Data from several of these studies have been included in this review as the pulmonary fate of atmospheric ultrafines has likely similarities with the pulmonary fate of nanomedicines (Geiser et al., 2008; Furuyama et al., 2009).

\subsubsection{Clearance mechanisms}

Various elimination pathways for nanoparticles exist in the lungs, including coughing, dissolution, mucociliarly escalator, translocation from the airways to other sites, phagocytosis by macrophages and neuronal uptake (Figure 3); but the quantitative relationship among these pathways has not yet been established (Muhlfeld et al., 2008).



Fig. 3. Pathways involved in nanocarriers absorption 
When a nanoparticle has landed on the airways, it first encounters the surfactant on the top of the airway lining fluid. The surfactant will enhance particle wetting thus helping it to sink into the fluid, passing first through the gel phase and then to the sol phase. Compared with sulphur colloidal particles $(220 \mathrm{~nm})$, human serum albumin molecules (HSA, $66 \mathrm{kDa}$ ) were cleared 3 times more slowly from the bronchi of dogs. This difference was attributed to the possibility that sulphur nanoparticles resided on the gel phase (i.e. the top layer of the periciliary fluid) whereas HSA dissolved and partitioned into the sol (i.e. bottom layer) which may be transported less effectively by mucociliary clearance (MCC). If extrapolated to inhaled drugs, the more soluble ones will behave like HSA and should be hence less susceptible to MCC (Edsbacker et al., 2008), but more likely absorbed through the epithelium. For nanoparticle agglomerates, it is likely that the particles will first reside on the gel phase. Depending on the aqueous dispersibility and solubility in the airway fluid, the agglomerates may remain in the gel phase behaving like the microsized particles, or they may then disperse into nanoparticles followed by dissolution and absorption. Nanoparticles delivered within a liquid droplet (e.g. from a nebulizer) might be different from dry particles, as the droplet liquid may interact with the gel layer making the nanoparticles easier to wet and partition into the sol layer, i.e. potentially more readily to escape the MCC (Zhang et al., 2011).

\subsubsection{Dissolution}

Dissolution depends on the site of deposition, which determines the volume of airway fluids available for dissolution and, hence, whether the dissolution occurs in sink or non-sink conditions, as well as on the solubility and dose of the drugs. Freely water soluble drugs include organic salts (e.g., salbutamol sulphate, terbutaline sulphate and disodium cromoglycate) and polar compounds (e.g. mannitol). These drugs will dissolve readily in the airway fluid followed by absorption or elimination by the mucociliarly escalator. Sparingly soluble drugs include the inhaled corticosteroids, which have aqueous solubility ranging from 140 to below $0.1 \mu \mathrm{g} / \mathrm{mL}$ (Edsbacker et al., 2008). Once dissolved, the drug molecules are diluted in the airway fluid where they can bind to proteins, opsonins, or other constituents and be metabolized and/or absorbed into the blood and lymph (Schmid et al., 2010).

Absorption of the drugs depends on the site such as alveolar or conducting airways (which affects the barrier thickness and surface area) and the drug molecule itself (which impacts on passive diffusion and active uptake by the epithelium. It must be pointed out that absorption of most drugs from the lungs is rapid: as an example, it has been reported that following inhalation of formoterol fumarate $(4.5 \mathrm{nmol} / \mathrm{L})$ and budesonide $(136 \mathrm{pmol} / \mathrm{L}$, the peak plasma concentrations occurred at 20 and $10 \mathrm{~min}$, respectively.

\subsubsection{Mucociliary clearance (MCC)}

MCC operates in the ciliated airways where the movement of the cilia transports the mucus carrying the drug nanoparticles or dissolved drug (not yet absorbed) on the epithelial surface towards the pharynx/larynx. The drug-containing mucus will then be swallowed to the GI tract. The average transport velocity in the human trachea has been estimated at 3-10 $\mathrm{mm} / \mathrm{min}$, but the value varies widely among subjects. Using well-developed techniques of depositing radiolabelled sulfur colloids in the central airways, Daviskas and her colleagues reported a MCC rate remarkably reduced in patients with bronchiectasis, asthma, and CF, 
with respect to healthy individuals. Actually, MCC and dissolution occur simultaneously and their relative importance should depend on the elimination rate from each of these contributions. While insoluble particles of $6 \mu \mathrm{m}$ are practically all cleared from the bronchial airways by MCC in $24 \mathrm{~h}$, smaller particles are retained for a longer period showing almost an inverse relationship between the $24 \mathrm{~h}$ airway retention and the geometric particle size. Nanoparticles with enhanced mobility may partition through the mucus into the periciliary spaces, where they can be taken up by the airway macrophages and bronchial epithelial cells, causing a reduction of MCC (Schmid et al., 2009).

\subsubsection{Macrophage uptake}

Alveolar macrophages are responsible for clearance of nanoparticles deposited in the alveolar region, in which MCC is absent. In response to the deposited nanoparticles, alveolar macrophages will migrate to the particles and phagocytize them via chemotaxis involving opsonisation. Macrophage uptake is believed to complete within 6-12 h after deposition of the particles in the alveoli (Oberdörster, 2007). nce internalized in the macrophages, the particles will be either disintegrated (e.g. by enzymes in lysosomes) or accumulated in the lymphatic system (Schmid et al., 2009) draining both airways and alveoli and finally terminating in the mediastinal and hilar lymph nodes (Geiser \& Kreyling, 2010). A minor fraction of the particle-carrying macrophages will migrate to the ciliated airways where they are removed by MCC (Schmid et al., 2009). However, with a retention half-time of up to 700 days in humans (Oberdörster, 2007), clearance of solid particles by alveolar macrophages is a relatively slow mechanism. Phagocytosis of particles below $100 \mathrm{~nm}$ is not effective (Oberdörster, 2007), most probably because of a less effective recognition $(\sim 20 \%)$ of nanoparticles by the macrophages (Schmid et al., 2009). The reduced recognition is possibly due to more scattered and diluted chemotactic signals as a result of i) higher number concentration of nanoparticles (compared with micron-sized particles at the same dose) and ii) fewer opsonin molecules available per particle. Conversely, since nanoparticles are more readily taken up by epithelial cells, they become less available to be phagocytized by macrophages (Madl \& Pinkerton, 2009). Macrophages are also present in the ciliated airway but their role in nanoparticle clearance is probably less important compared with MCC.

\subsubsection{Translocation into cells, blood and lymph}

This process involves transcytosis of the particles into the epithelial cells and/or across the epithelia of the respiratory tract into the interstitium and then to blood and lymph. As described earlier, translocation to the lymphatic system can be facilitated by macrophage uptake. The transport may be protein-mediated, requiring binding of certain proteins on the nanoparticle surface for recognition by the receptors (Schmid et al., 2009). The transport may also be receptor-mediated transcytosis via caveolae (Oberdörster, 2007), which have a diameter of 50-100 nm. Surface coating of the particles by albumin and lecithin may facilitate cellular uptake by pneumocytes and transcytosis across capillaries (Yang et al., 2008). Once internalized, nanoparticles can bind to mitochondria and even DNA in the nucleus (Muhlfeld et al., 2008; Oberdörster, 2007).

When translocated to the systemic circlulation, nanoparticles could cause unwanted effects on the blood (e.g. accumulation in platelets) and other organs in the body (Oberdörster, 2007). Some biological effects may include inflammation, oxidative stress, cytotoxicity, fibrosis, and immunologic responses ( Madl \& Pinkerton, 2009; Unfried et al., 2007). 
Surface area has been proposed as the single most important particle dose parameter for the toxicity of nanoparticles (Schmid et al., 2009). This is particularly relevant for inflammatory and oxidative stress reactions, such as surface area of a catalyst (i.e. nanoparticles), that determines the oxidative reaction rate. However, oxidative stress involves the formation of reactive oxygen species (ROS) from the particles containing reactants such as transition metals or polyaromatic hydrocarbons (which induce the expression of the CYP1A1 protein). Drug nanoparticles, which do not contain such reactants, are therefore less likely to cause oxidative stress in the lungs. Biodegradabile nanoparticles indeed showed significantly lower inflammatory response in-vitro (Sung et al., 2007). Interestingly, translocation in the reverse direction with particles re-entrained from the lung capillaries or interstitium to the luminal side of the epithelium have been shown in animal models using rabbits and rats. Such back-translocation was suggested to be macrophage-mediated.

\subsubsection{Neuronal uptake}

Translocation into afferent vagal nerves in the tracheobronchial airways has been proposed but still not well studied (Oberdorster et al., 2005). Nanoparticles deposited in the nasal cavity have been reported to be taken up by the olfactory lobe and translocated to the central nervous system (Oberdorster et al., 2005). However, such a neuronal uptake pathway is relevant only if the drug nanoparticles are inhaled nasally. Existing data from epidemiologic and toxicological studies showed longer retention of inhaled nanoparticles in the lungs, but the applicability of these findings on nanoparticles is under investigation. In theory, inhaled nanodrug particles have the potential to be retained longer in the lungs followed by cellular uptake and translocation into the systemic circulation thus causing nanotoxicity. It can be speculated that the fate of the nanoparticles in the lungs, regarding the elimination pathways, will depend on the properties of both the particle and the drug molecule. Micron-sized aggregates of nanoparticles will deposit by sedimentation in the tracheobronchial (TB) region where MCC will operate to eliminate both the dissolved and undissolved drugs. Even discrete nanoparticles can deposit by diffusion in the TB region. Drug nanoparticles deposited in the alveolar region will dissolve in the airway fluid and be absorbed. This is likely to be the case even for hydrophobic drugs with low aqueous solubility like inhaled corticosteroids due to the relatively low doses that are used. As a result of the low persistence of drug nanoparticles, dissolution and mucociliary escalator will likely be the major clearance pathways responsible for these particles before macrophage phagocytosis and other translocation pathways would start to play a significant role.

\section{Nanocarriers for lung delivery}

Nanomedicine can be defined as the application of nanotechnology to medicine. Nanotechnology involves the understanding and control of matter at dimensions of 1 to 100$200 \mathrm{~nm}$, where unique phenomena enable novel applications. Artificial nanostructures are of the same size as biological entities and can readily interact with biomolecules on both the cell surface and within the cell (Figure 4). Here our attention is focused on the fate of nanomedicines delivered to the lung, in particular an innovative glucocorticoid delivery system will be considered.

The understanding the fate of nanomedicines in the lungs is important because fate and therapeutic activity are closely related. Interaction of nanomedicines with cells of the 


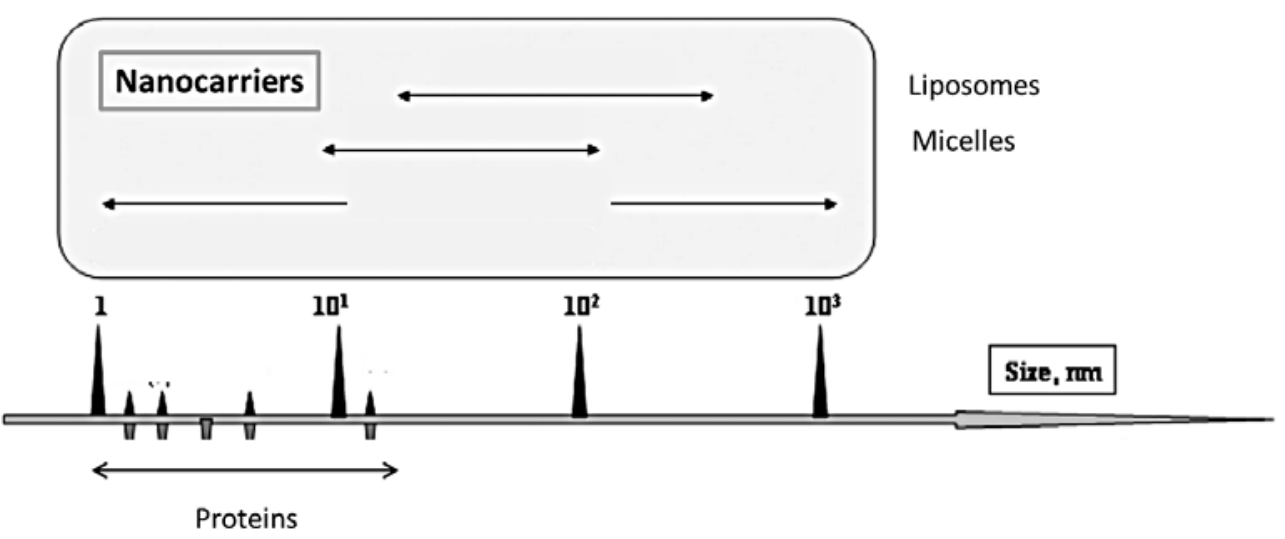

Fig. 4. Nanocarrier size

respiratory system will determine the pharmacodynamic response. For instance, the rapid uptake of particles by alveolar macrophages can be a way of targeting anti-tuberculosis drugs to this type of cells (Nimje et al., 2009). Conversely, macrophages uptake represents a clearance pathway for drugs acting on other cells within the lungs (e.g., $\beta_{2}$ mimetics).

Nowadays, biopharmaceuticals and conventional drugs are frequently engineered or incorporated in carriers in order to direct their fate in preferential pathways (Schmidt, 2009; Veronese \& Pasut, 2005). Nano-size drug carriers can incorporate various therapeutics (e.g.,poorly water soluble drugs) and present several advantages for drug delivery to the lung including controlled release, protection from metabolism and degradation, decreased drug toxicity and targeting capabilities. Moreover, the successful integration of novel drugs with devices capable of delivering defined doses to the respiratory tract has resulted in a proven track record for inhalation as a route of administration that limits systemic exposure and provides localized topical delivery. Thus, a number of orally inhaled products have been successfully developed over the last 50 years, providing symptomatic relief to millions of patients with asthma and chronic obstructive pulmonary disease (COPD).

There are numerous types of nanoparticle systems now being explored for drug delivery to lungs, especially in cancer treatment (Haley \& Frenkel, 2008).

The types of nanoparticle used at present in research for cancer therapeutic applications include polymeric nanoparticles, protein nanoparticles, ceramic nanoparticles, viral nanoparticles and metallic nanoparticles (Balak et al., 2010).

Liposomes are the most extensively investigated system for controlled drug delivery to the lungs (Mansour et al., 2009). A few liposome-encapsulated antibiotics have been delivered to the lungs in phase II clinical trials. These include amikacin (Weers et al., 2009) and ciprofloxacin (Bruinenberg et al., 2010) Multiple treatment cycles with ARIKACE ${ }^{\text {TM }}$ (liposomal amikacin for inhalation) showed sustained improvement in lung function with significant reduction in bacterial density in CF patients who have chronic Pseudomonas lung infections (Okusanya et al., 2009).

A nanoscale liposomal formulation of amikacin has been shown to slowly release the drug in rat lungs and to penetrate Pseudomonas biofilms and CF sputum in vitro (Meers et al., 2008). 
Mitsopoulos and Suntres reported that the delivery of N-acetylcysteine as a liposomal formulation improves its effectiveness in counteracting Paraquat-induced cytotoxicity (Mitsopoulos \& Suntres, 2011).

Liposomal drug dry powder formulations, realized to obtain novel devices capable of delivering defined doses of drugs, represent promising tools for pulmonary drug administration, such as selective localization of drug, reduced local and systemic toxicities, increased patient compliance and high dose loading.

In liposomal dry powder formulations, drug encapsulating liposomes are homogenized, dispersed into the carrier and converted into dry powder by using freeze drying, spray drying or supercritical fluid technologies.

The most commonly used liposomes are composed of lung surfactants and synthetic lipids. Liposomal formulation have been proposed to delivery anticancer drugs, corticosteroids, immunosuppressants, antimicotic drugs, antibiotics for local pulmonary infections and CF and opioid analgesics for pain management using. Many of them have reached the stage of clinical trials for the treatment of several pulmonary diseases (Misra et al., 2009).

A promising application of nanocarriers to lung targeting is related to gene delivery. Gene therapy is currently being developed for a wide range of acute and chronic lung diseases, incuding CF, cancer and asthma (Griesenbach \& Alton, 2009; Lam et al., 2011). Nguyen et al (2009) developed a highly efficient nanocomposite aerosol for pulmonary gene delivery, consisting of a biodegradable polymer core.

Respiratory diseases have attracted particular attention as targets of siRNA - mediated therapeutics, due to the lethality and prevalence of certain illnesses and the lung's accessibility to therapeutic agents via both local and systemic delivery routes. However, one of the major challenges to realize the RNAi therapeutic potential in lung diseases is to deliver the siRNAs to the lung tissue, in particular, to the target cells with high efficiency and high specificity (Yuan et al., 2011).

Several clinical trials have been conducted in order to assess the efficacy and safety of pulmonary DNA delivery using viral and non-viral vectors, especially in the case of CF. Yet, none of these formulations have been pursued due to low transfection efficiency, transient gene expression or immune elimination of the gene vector. Identifying the barriers to cell transfection might help to improve gene transfer efficiency of non-viral vectors (Griesenbach \& Alton, 2009). An efficient and safe cationic lipid, 6-lauroxyhexyl lysinate (LHLN), was proposed to prepare cationic liposomes. In vitro tests showed that, compared with Lipofectamine2000, the new cationic liposome formulation using LHLN exhibited lower cytotoxicity and similar transfection efficiency in A549 and HepG2 lung cancer cells (Peng et al., 2011).

Ishitsuka et al. (2011) developed a multifunctional envelope-type nano device (MEND), in which plasmid DNA is condensed using a polycation to form a core particle that is encapsulated in a lipid envelope, modified with the IRQ peptide (IRQRRRR) to enhance transgene expression in lungs. (Ishitsuka et al., 2011).

Clinical applications of liposomes and nanoparticles for drug delivery to the respiratory tract are still in early stages. The key to future innovation may lie at the interface between biology and particle engineering. Improved understanding of biological processes 
including particle clearance, cellular targeting, intracellular trafficking, and drug absorption are needed to better design formulations that deliver to the "target" with the optimal balance of pharmacodynamic, pharmacokinetic, and safety profiles. More specifically, continued advances are needed in the development of: (1) controlled release formulations; (2) formulations with improved regional targeting within the lungs (e.g., airway versus alveoli and vice versa); (3) formulations containing active targeting moieties; (4) formulation strategies for improving the systemic bioavailability of inhaled macromolecules; (5) formulation strategies for delivering macromolecules, including siRNA and DNA, into cells; and (6) formulations with improved dose consistency. It is likely that such innovation will require the development of novel excipients and particle engineering strategies. Future innovation must also take into account the changing marketplace and the diverse set of customers (patient, healthcare professional, heath authorities, payers, and politicians) who must be satisfied. The pharmacoeconomics of new delivery systems will be closely scrutinized, so it is imperative that cost factors should be taken into account. Otherwise, the new technology option may overshoot the evolving inhalation marketplace.

\section{Toxicity of nanoparticles to the lung}

Epidemiological studies have confirmed a positive correlation between levels of particulate pollution and increased morbidity and mortality rates among general populations (Gwinn \& Vallyathan, 2006; Stone et al., 2007).

The adverse health effects seem to be dominated by pulmonary symptoms. For instance, many reports have addressed that occupational exposure of inhaled rigid nanoparticles (NPs) can lead to respiratory diseases such as pneumoconiosis (pulmonary fibrosis) and bronchitis (Byrne \& Baugh, 2008; Lkhasuren et al., 2007).

Increasing inhalation of ambient ultrafine particles has been linked with exacerbation of respiratory symptoms and mortality among COPD sufferers (Xia et al., 2009). It has also been documented that NPs can instigate oxidative stress and cellular toxicity in various types of cells (Huang et al., 2009).

It was also reported that chronic exposure to NPs can potentially predispose humans to lung inflammation and increase the risk of COPD.

A concentration range of NPs within the level found in ambience and in nanotechnology industries (Klaine et al., 2008) can promote mucin aggregation.

The second safety aspect of deep lung deposition is the interaction of nanoparticles with the alveolar environment. The alveolar space is covered with a thin surfactant film. This film has important physiological functions e.g. to accelerate gas exchange and to lower the surface tension in the alveolar space. Compromising these functions by inhalable nanoparticles might cause life threatening consequences. Therefore, the compatibility of a delivery system with the alveolar environment must be considered (Azarmi et al., 2008).

For these reasons vesicular nanocarriers, composed of lung surfactants and/or synthetic amphiphiles, provide an efficient delivery system for the treatment of pulmonary disorders due to their biocompatibility, biodegradability and non-toxic nature (Taylor \& Newton, 2004). 


\section{Chronic obstructive pulmonary disease (COPD)}

COPD is the fourth leading cause of death in the United States and Europe, with COPD mortality more than doubling in the last two decades (Mannino et al., 2002). COPD can be defined as a preventable and treatable disease state characterized by airflow limitation that is not fully reversible. The airflow limitation is usually progressive and is associated with an abnormal inflammatory response of the lungs to noxious particles or gases, primarily caused by cigarette smoking. Although COPD affects the lungs, it also produces significant systemic consequences (Celli \& MacNee, 2004). It is interesting to point out how the definition of COPD has evolved including the systemic consequences of the disease. The natural history of the disease reveals numerous extrapulmonary manifestations and comorbidity factors that complicate the evolution of COPD, thereby altering the prognosis and quality of life of patients (Barnes \& Celli, 2009; Agusti \& Soriano, 2008). Many extrapulmonary effects of COPD have been described over the last two decades, including renal and hormonal abnormalities, muscle wasting (Remels et al., 2007), osteoporosis, anemia and reduction in circulating bone marrow progenitors (Palange et al., 2006). Although these systemic manifestations have been described for years in COPD patients, it is still unclear whether they represent consequences of the pulmonary disorder, or whether COPD should be considered as a systemic disease. The importance of establishing the distinction between a respiratory disease with extrapulmonary manifestations and a systemic inflammatory state with multiple compromised organs is justified by different therapeutic options: in the first definition, therapy is primarily centred on the lungs, whereas in the second, therapy could aim at the systemic inflammatory state. Both submucosal gland hypertrophy and airway surface goblet cell metaplasia are prominent features of the chronic bronchitis that occurs in most COPD patients. While cough and chronic expectoration helps to remove excess mucus from the large airways, impaired mucociliary function in COPD causes ineffective mucus clearance from small airways ( $\leq 2 \mathrm{~mm}$ diameter) which are not well cleared by cough. Like asthma and CF, COPD is strongly associated with the accumulation of inflammatory mucous exudates in the lumens of small airways (Hogg et al., 2004). Accordingly, declining lung function, respiratory infections, hospital admission, and mortality are significantly associated with chronic expectoration.

Among the numerous extrapulmonary effects of COPD, systemic inflammation has been widely studied and considered as an important key between the pulmonary disease and the related systemic manifestations. Many studies reported changes in various inflammatory cells and mediators, including neutrophils, lymphocytes, acute-phase reactants, and cytokines. Recently it was shown that systemic inflammation is present during COPD exacerbations and stable phases of the disease: increased numbers of leukocytes, levels of acute-phase response proteins (C-reactive protein and fibrinogen), cytokines such as interleukin (IL)-6, and tumor necrosis factor (TNF)- $\alpha$ are present in the peripheral blood of COPD patients (Gan et al., 2004). Systemic inflammation has been implicated in the pathogenesis of the majority of COPD systemic effects, including weight loss (Wouters, 2002), skeletal muscle dysfunction, cardiovascular diseases (Sin \& Man, 2003), and osteoporosis, although it is still controversial whether this so called low-grade systemic inflammation represents the consequence of pulmonary inflammation into the systemic vascular bed (Agusti et al. 2003), or whether it is a systemic inflammation. Although inflammation is certainly one of the major features of COPD, we still need to understand 
whether the local inflammation is sufficient to induce systemic effects, or whether a second pathogenetic event is required (Evans \& Koo, 2009; Huertas \& Palange 2011).

Over the years it was evidenced that mucus hypersecretion is an important manifestation of COPD. In the classical phenotype of chronic bronchitis, mucus hypersecretion is the key presenting symptom that appears independent of airflow obstruction. A more recent work demonstrated that obstruction of the small airways by inflammatory exudates containing mucus is predictive of early death after volume reduction surgery in patients with advanced COPD (Hogg et al., 2007). It was suggested that such occlusion enhanced the probability of infection in the lower respiratory tract. In addition, several epidemiological studies showed an association between mucus hypersecretion and outcomes in patients with COPD. Mucus hypersecretion is not an innocent disorder. However, despite these observations, until now few studies have focused on the effects of mucolytic drugs in patients with COPD, even though some of these mucolytic drugs also appear to have antioxidant properties (Dekhuijzen, 2004; Rahman et al., 1997; Rahman \& Kilty 2006; Decramer \& Janssens, 2010).

Histopathological findings from surgical specimens clearly show that increased goblet cell numbers and increased MUC5AC and MUC5B production and secretion are found in the lumen of small airways in COPD patients (Caramori et al., 2004). These findings are inversely associated with pre-surgical Forced Expiratory Volume in the $1^{\text {st }}$ second (FEV1). Thus, patients with higher FEV1 have less goblet cell metaplasia than patients with lower FEV1, suggesting that the presence of mucin-producing cells in the airways is related to increased airflow obstruction. The presence of a prominent goblet cell phenotype also negatively correlates with FEV1 improvement following lung volume reduction surgery (Kim et al., 2005). Collectively, these results show that mucus secretion may be significant enough to result in physiologically and clinically measurable mechanical obstruction of small airways, and it may significantly impact disease pathogenesis and prognosis. The main cause of COPD in humans is cigarette smoking. In mice, chronic cigarette smoke exposure causes strain dependent mucous metaplasia. Cigarette smoke itself has also been shown to promote mucin synthesis directly in vitro by activation of the EGFR cascade (Shao et al., 2004). Inhalation, of one of the many potential toxicants present in cigarette smoke, acrolein (acrylic aldehyde), induces mucous metaplasia and MUC5AC production in animals. Acrolein also induces MUC5AC production in human airway epithelial cell lines, and it is found at significantly elevated levels in the induced sputum and exhaled breath condensates of COPD patients, (Deshmukh et al., 2008).

It has been suggested that mucus can also serve as a suitable medium for adherence and growth of some bacterial pathogens, such as non-typeable H. influenzae. Gram positive and gram negative bacteria products up-regulate MUC5AC and MUC2 gene expression and mucin secretion in human respiratory epithelial cell lines in vitro, and the same effect can be seen in some animal models in vivo. Viral infections are also closely associated with COPD exacerbations in humans (Wedzicha \& Donaldson, 2003; Beckham et al., 2005). Surgical specimens from smokers with COPD show increased goblet cell numbers in the epithelium of peripheral airways compared to non-smokers. This is accompanied by increased macrophages and CD8 positive T-lymphocytes, both of which are indicative of viral. Roles for IL-6 and virus-induced mucin overproduction have been suggested. In vivo, IL-6 production is enhanced during the early phase of bacterial or viral-induced inflammation. 
Accordingly, IL-6 levels are increased in COPD patients (Bucchioni et al., 2003), and during experimental respiratory viral infections in humans and mice (Decramer \& Janssens, 2010).

\subsection{Mucus rheological properties}

Mucus rheology plays a critical role in maintaining respiratory health. Mucins are large, highly glycosylated proteins. The polyanionic nature of mucin stems primarily from sialic acid, sulfate, and carboxyl groups present in these linked oligosaccharides. Beside physical entanglement, cationic calcium ions can act as crosslinkers that condense the mucin matrices inside mucin granules before exocytosis. Upon release, phase transition mainly driven by the Donnan effect triggers the massive decondensation of mucin networks. Hydrogen bonding, hydrophilic and hydrophobic interactions have also been proposed to contribute to the gel properties of mucin The gel characteristics and rheological properties of mucin are critical for the maintainance the integrity of epithelia by trapping bacteria and viruses and for mucociliary clearance (Bansil \& Stanley, 1995; Verdugo, 1990).

Mucus is mainly composed of large and heavily glycosylated glycoproteins called mucins. The gel-forming mucins rapidly hydrate after exocytosis and, due to their tangle network properties, anneal with other mucins to form a protective barrier at the airway-surface liquid layer. The mucin gel layer lines the epithelial surface of various organs such as the vaginal tract, eyes, gastric wall and pulmonary lumen. Mucus in the airway of lungs serves as an innate immune defense against inhaled particulates, bacteria and viruses. Maintenance of the airway protection mechanism stems from the delicate balance between normal mucus production, transport and clearance. The mucin polymer network of mucus has a characteristic tangled topology. Since the rheological properties of mucus are governed mainly by the tangle density of mucin polymers, which decreases with the square of the volume of the mucin matrix, the mucin network hydration (degree of swelling) is the most critical factor in determining the rheological properties of mucus. The diffusivity of mucin matrices, which is closely related to mucin viscosity, can be calculated from polymer swelling kinetics. Based on the polymer network theory, polymer diffusivity is inversely proportional to its viscosity (Lodge, 1999). Thus, lower rate of mucin diffusivity is associated with higher viscosity, less dispersed and less transportable mucins that appear to characterize the clinical symptoms of thick mucus accumulation and obstruction commonly found in asthma, COPD and CF 44. (Rogers, 2007).

The clinical manifestation of major respiratory diseases (Rogers \& Barnes, 2006; Quinton, 2008) are related to thick mucus.

The relationship between mucin dehydration and defective mucus clearance has been well established (Mall et al., 2004). As a result, the poorly hydrated, highly viscous and less transportable mucus appears to accumulate within airway passages (Randell et al., 2006). Obstruction of airway lumen with viscous mucus is usually accompanied by chronic bacterial infection, inflammation and impaired mucociliary transport.

\section{Case studies}

Although the use of liposomes for aerosol formulations is certainly encouraging, liposome nebulization still presents some problems, i.e. storage stability (mainly related to oxidation processes) and leakage of encapsulated drugs. In addition, it should be also considered that 
synthetic phospholipids are usually expensive and, on the other side, natural phospholipids show a variable degree of purity (Desai \& Finlay, 2002).

An alternative approach to the liposomal approach is the use of liposome-like vesicles made up of non-ionic surfactants, the so-called niosomes. These carriers were proposed for both topical (Carafa et al., 2000; Carafa et al., 2004; Paolino et al., 2007; Paolino et al., 2008) and systemic administration (Cosco et al., 2009).

Here we report the evaluation of the possible advantages of a new type of non-phospholipid vesicle system for pulmonary drug delivery that can lead to an improved mucus permeation. Vesicles consisting of one or more surfactant bilayers enclosing aqueous spaces (non ionic surfactant vesicles NSVs), are of particular interest because they offer several advantages with regard to chemical stability, lower cost and availability of materials compared to conventional liposomes

In the formulation of inhaled drugs for the treatment of asthma and COPD, considerable attention has been devoted to new aerosol morphologies which can either enhance the local effect and/or increase the penetration through the mucus, secreted in bronchial inflammatory diseases. In diseases characterized by bronchial hypersecretion, lipophilic substances, such as corticosteroids, can be remarkably impeded in reaching their receptors, which are localized within the cytoplasm of bronchial epithelial cells.

In particular, alveolar macrophages are important target cells for the therapeutic action of glucocorticoids, because these cells are the major source of both proinflammatory and antiinflammatory cytokines. The action of glucocorticoids is mediated by an intracellular receptor belonging to the steroid thyroid/retinoic acid receptor superfamily (Oakley et al., 1999).

With the purpose of carrying out research leading to an innovative formulation for lung delivery capable of permeating the mucous layer and of an efficient delivery to alveolar macrophages, beclomethasone dipropionate (BDP), clinically used for the treatment of asthma and COPD, was entrapped in non-phospholipid vesicles.

$\mathrm{BDP}$, as a reference model drug, was encapsulated in vesicular structures obtained with polysorbate 20 . The aim of the study was to evaluate in vitro the effectiveness of such delivery system that should enhance permeation through mucosal barriers because of the presence of vesicles formed with a remarkably hydrophilic non-ionic surfactant usually considered as unsuitable for the formation of vesicular structures because of its high HLB value (HLB 16.7) (Santucci et al., 1996).

The intracellular availability of BDP and the safety of the delivery system are the two main issues to be addressed to propose these innovative non-ionic surfactant vesicles as carriers for the pulmonary delivery of this drug to be effectively used for the treatment of pulmonary inflammatory diseases. Therefore, the aim of this investigation was the evaluation of the interaction between our innovative non-ionic surfactant vesicles and human lung fibroblast (HLF) cells, the carrier tolerability, the vesicle localization within the cells and the amount of BDP actually internalized by the cells.

Unilamellar vesicles were obtained from a non-ionic surfactant/BDP aqueous dispersion (Hepes pH 7.4) by means of the "film" method as previously reported (Santucci et al., 1996), according to the compositions reported in Table 1. 


\begin{tabular}{|c|c|c|c|}
\hline Sample & Polysorbate 20 & Cholesterol & BDP \\
\hline 1 & 1.84 & 0.58 & 0.5 \\
\hline 2 & 1.84 & 0.58 & 1.0 \\
\hline 3 & 1.84 & 0.58 & 3.0 \\
\hline 4 & 1.84 & 0.58 & 5.0 \\
\hline 5 & 3.68 & 1.16 & 0.5 \\
\hline 6 & 3.68 & 1.16 & 1.0 \\
\hline 7 & 3.68 & 1.16 & 3.0 \\
\hline 8 & 3.68 & 1.16 & 5.0 \\
\hline
\end{tabular}

Table 1. Sample composition (expressed as $\% \mathrm{w} / \mathrm{v}$ )

All compositions are able to form nanovesicles with different size and zeta potential ( $\zeta$ potential) according to the various formulations (Table 1). The size and the polydispersity index (PDI) obtained by dynamic light scattering measurements indicated those formulations with the smallest size and the most homogeneous nanovesicles population that can be obtained: samples 2 and 8 , chosen to perform further experiments.

Size measurement experiments indicate that BDP-loaded vesicles are slightly larger than empty ones as reported in Table 2 for samples 2 and 8 of Table 1, there is an increase in diameter between 10 and $20 \%$, and this expected effect can be related to drug partition between the bilayer and the aqueous core of the vesicles. Accordingly, the presence of BDP in the formulation may affects the $\zeta$-potential values; as it is possible to observe from Table 2 , the corresponding samples 2 and 8 show a significant decrease in $\zeta$-potential that approaches the value obtained with BDP alone. This effect can be related to the chemical steroidic structure of the drug that is somehow similar to that of cholesterol, thus allowing it to fit well within the vesicular structure.

\begin{tabular}{|l|l|l|}
\hline Sample & Dimensions $(\mathrm{nm})$ & $\zeta$-potential $(\mathrm{mV})$ \\
\hline 2 & $163 \pm 0.03$ & $-32 \pm 0.2$ \\
\hline 8 & $174 \pm 0.02$ & $-34 \pm 0.3$ \\
\hline Empty vesicles & $146 \pm 0.05$ & $-40 \pm 0.2$ \\
\hline BDP solution $0.05 \% \mathrm{w} / \mathrm{v}$ & $=$ & $-30 \pm 0.1$ \\
\hline
\end{tabular}

Table 2. Vesicle dimensions $(\mathrm{nm})$ and $\zeta$ - potential $(\mathrm{mV})$ of analyzed samples $(n=3 ; \pm S D)$

Furthermore, it should be pointed out that electron microscopy carried out on numerous samples (10) indicated that nebulization does not influence drug-loaded vesicle dimensions (Figure 5A and B).

Analyzed samples showed a good stability in terms of possible changes in vesicle dimensions after aggregation.

Size measurement experiments indicated that after 1 month at $25^{\circ} \mathrm{C}$, no appreciable vesicle dimension variations could be detected.

The best entrapment efficiency (e.e.) was obtained for sample 8 and the calculated drug e.e. indicated that only about $20 \%$ of the overall amount of BDP is actually enclosed within the vesicles. This result is in agreement with the data reported by previous authors (Montenegro 

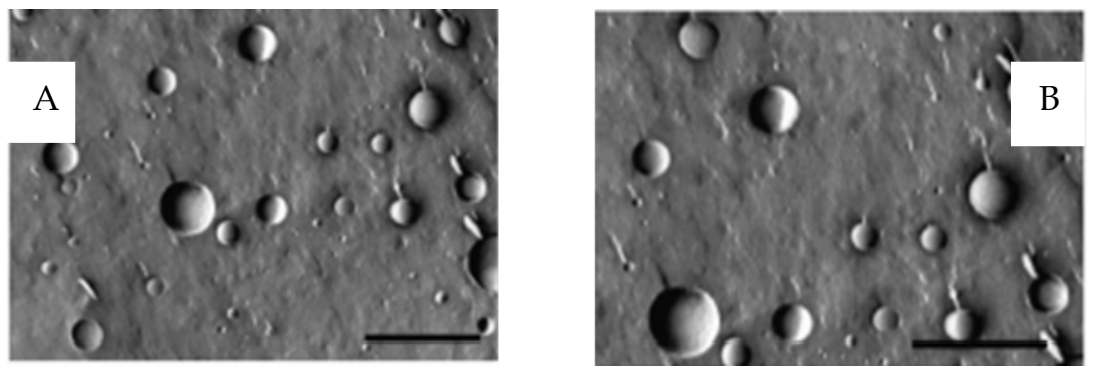

Fig. 5. Trasmission electron micrographs of BDP-loaded vesicles after freeze-fracture, before (A) and after (B) nebulization. The scale bar represents $0.5 \mu \mathrm{m}$.

et al., 1996; Darwis et al., 2001). For this reason, for permeation and nebulization experiments the formulation corresponding to sample 8 of Table 1 was used.

The possibility to use the novel vesicular dispersion in a conventional jet nebulizer, widely used in clinical applications, was also evaluated. For this purpose, samples were characterized also by means of rheological measurements and the aerodynamic diameter was determined (Table 3) as well as the nebulizer mass output (Figure 6) after completion of nebulization. Evaluation of Mass Median Aerodynamic Diameter $(2.0 \pm 0.2 \mu \mathrm{m})$ and of geometric standard deviation (GSD) were also carried out; the GSD value (1.5) demonstrates the polydisperse nature of the distribution of the aerosolized droplets that, on the other side, contained a monodisperse vesicular system.

\begin{tabular}{|l|l|}
\hline Aerodynamic diameter & Percentage \\
\hline$<10$ & 100 \\
\hline$<5$ & 99.5 \\
\hline$<2$ & 65 \\
\hline
\end{tabular}

Table 3. Percentage of particles with aerodynamic diameter $<10,<5,<2 \mu \mathrm{m}$, containing non-ionic surfactant vesicles, delivered by a jet nebulizer

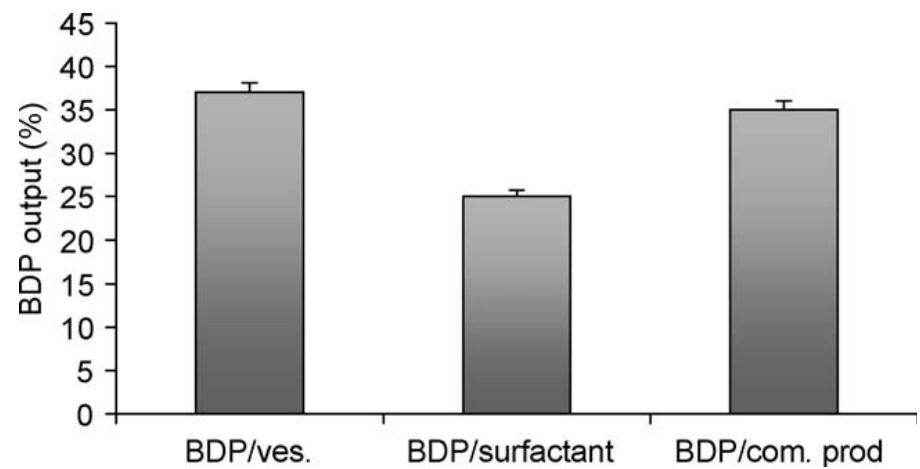

Fig. 6. Deposition of vesicle-encapsulated BDP (BDP/ves) on filters upon nebulization, compared to a BDP/surfactant solution and to a BDP commercial product ( $n=3, \pm S D)$. 
Furthermore, in all conditions of nebulization (TurboBoy nebulizer and Clenny nebulizer), the dispersion $\mathrm{BDP} /$ vesicles releases a greater amount of drug, dosed by HPLC, with respect to commercial formulations.

An important aspect to be taken into account for an actual application of these non-ionic surfactant vesicles as possible carriers to be aerosolized for the pulmonary delivery of drugs is their colloidal and storage stability.

In fact, the occurrence of aggregation phenomena can lead to a significant worsening of the biopharmaceutical features of nanosized colloidal suspensions, such as NSVs. Therefore, the colloidal stability of BDP-loaded NSVs was evaluated using the Turbiscan Lab® Expert (Celia et al., 2009) i.e. the optical transmission and the photon backscattering profiles of various samples were recorded. Any variation of the vesicle volume fraction (migration) or mean size (coalescence) triggers the variation of backscattering (BS) and transmission (T) signals, which are graphically reported as positive (backscattering/transmission increase) or negative (backscattering/transmission decrease) peaks. It can be assumed that no variation of particle size occurs when the $\Delta \mathrm{BS}$ and $\Delta \mathrm{T}$ profiles are within an interval of $\pm 2 \%$ while variations greater than $10 \%$ either as a positive or a negative value are representative of an instable formulation.

Two different BDP concentrations, i.e. $50 \mathrm{mg} / \mathrm{ml}$ (sample BDP-50) and $0.4 \mathrm{mg} / \mathrm{ml}$ (BDP-0.4), were used in this stability investigations. The first concentration led to the maximum possible amount of drug entrapment within the NSVs, while the second concentration led to an amount of entrapped drug similar to that actually present in the most common commercial products.

The $\Delta \mathrm{BS}$ and $\Delta \mathrm{T}$ profiles of BDP -loaded and unloaded non-ionic surfactant vesicles are shown in Figure 7.

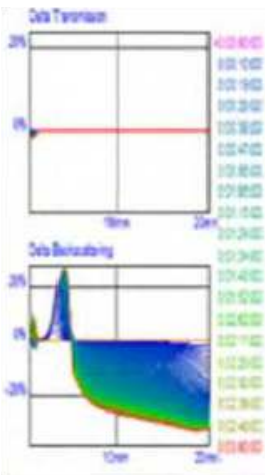

1



2

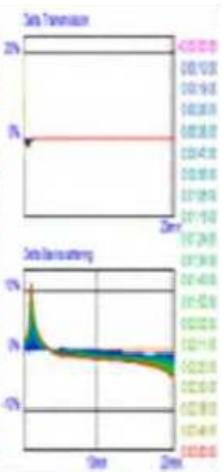

3

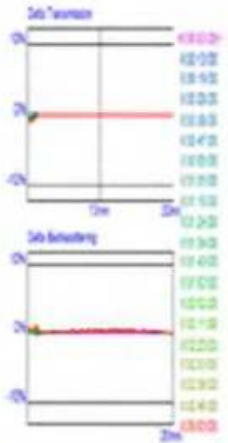

4

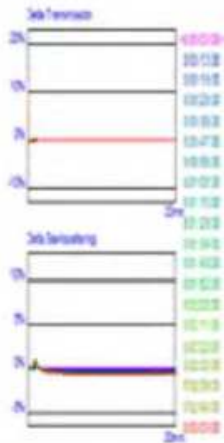

5

Fig. 7. Transmission and backscattering profiles of niosomes by using Turbiscan Lab® Expert. The image represents the analysis of different formulations: (1) unpurified BDP-50niosomes; (2) purified BDP-50-niosomes; (3) unpurified BDP-0.4-niosomes; (4) purified BDP0.4 -niosomes; (5) unloaded niosomes. Data are reported as a function of time $(0-3 \mathrm{~h})$ and sample height (from 2 to $20 \mathrm{~mm}$ ). 
The transmission signal remained close to the base line value and $\Delta \mathrm{T}$ profiles close to $0 \%$ were observed for all the investigated NSV formulations during the entire time of analysis.

Therefore, NSVs suspensions maintained a constant opalescent aspect along the height of various samples. At the same time, positive or negative variations of the backscattering profiles of the different formulations (Figure 7) were not correlated to destabilization processes under the sample height of $2 \mathrm{~mm}$ and over that of $20 \mathrm{~mm}$, the values having been determined by enclosed air in the bottom and/or on the top of the cylindrical glass tube, respectively. Different NSVs formulations showed that backscattering emerged as the prevalent signal in the different measurements (Figure 7). $\triangle \mathrm{BS}$ signals are close to $\sim 1 \%$ during the time of analysis for the entire height of the samples of both purified BDP-loaded and unloaded non-ionic surfactant vesicles (Figure 7 panels B, D and F). It was interesting to observe that the different amounts of the entrapped drug do not influence the colloidal stability of non-ionic surfactant vesicles both in terms of vesicle migration and coalescence. Different stability behaviors, as shown by $\triangle \mathrm{BS}$ profiles (Figure 7 panels $\mathrm{A}$ and $\mathrm{C}$ ), were observed in the case of not purified BDP loaded non-ionic surfactant vesicles (i.e. before gel exclusion chromatography).

In particular, vesicles prepared in the presence of the highest drug concentration (50 $\mathrm{mg} / \mathrm{ml}$ ) showed a high colloidal instability just after the beginning of the analysis. A moderate stability ( $\triangle \mathrm{BS}$ profile within the $10 \%$ during the $3 \mathrm{~h}$ of analysis) was observed for unpurified non-ionic surfactant vesicles prepared in the presence of $0.4 \mathrm{mg} / \mathrm{ml}$ of the drug, while an elevated stability (equal to purified formulations) was observed for unpurified unloaded vesicles (Figure 7 panel E). These findings can be due to the presence of high amount of free drug, that with time leads to the formation of aggregates. Therefore, the purification procedure is essential to achieve a stable vesicular colloidal carrier for the delivery of BDP. The stability findings by Turbiscan Lab® Expert measurement were also supported by light scattering size analysis during a storage period of 3 months, which showed no appreciable vesicle size variation for purified BDP-loaded non-ionic surfactant vesicles.

According to the aim of this research, the capability of ensuring a better penetration through the mucus layer of vesicular formulation was tested.

In Figure 8, the permeation rate of BDP from the vesicular dispersion is reported and compared with that obtained using a $\mathrm{BDP} /$ polysorbate 20 (at the same concentration used for vesicle preparation) suspension as well as with that of the commercial preparation. The vesicular formulation (BDP-0.4) was used in its unpurified form, thus with the drug partitioned inside and outside the vesicular structure.

This situation allows an appropriate comparison with the other preparations used in permeation experiments: since both micellar surfactant solutions and the commercial one contained free BDP and BDP included within aggregated structures (micelles). As it can be observed, the presence of NSVs in the formulation remarkably increases the permeation rate through the model mucosal barrier with respect to the other tested preparation thus indicating that the novel BDP formulation can be proposed for a better targeting of corticosteroids in the treatment of COPD.

An important aspect to evaluate an innovative drug delivery system is its safety. This aspect is much more relevant in the case of pulmonary delivery, since several side effects may 


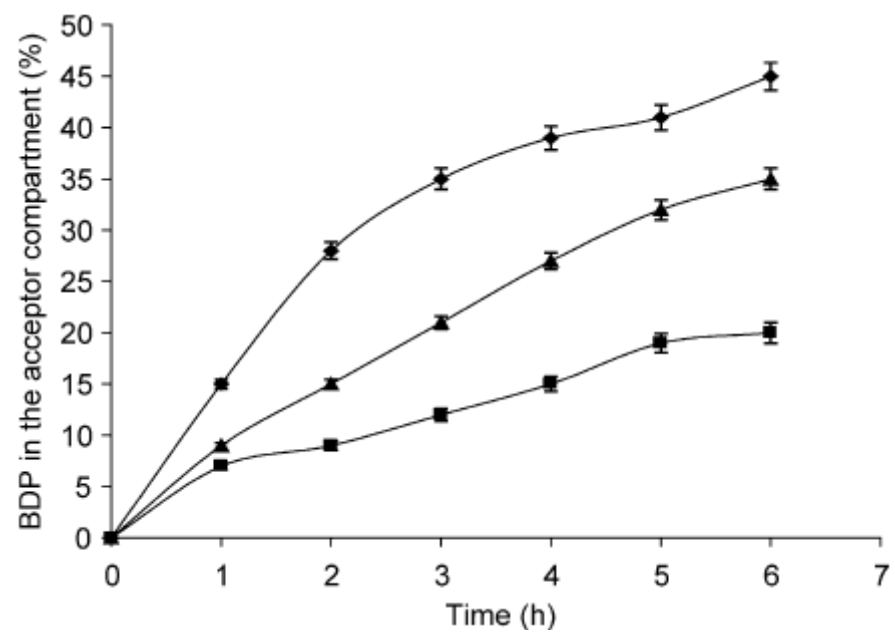

Fig. 8. Comparison of the permeation patterns through a gel-like mucin solution $(0.1 \% \mathrm{w} / \mathrm{v})$, expressed as percentage of permeated drug as a function of time $(n=3, \pm S D)$

$(\boldsymbol{B D P} /$ surfactant $\boldsymbol{\Delta} \mathrm{BDP} /$ commercial product $\diamond \mathrm{BDP} /$ vesicles).

result from an unsafe material, i.e. fibrosis, pulmonary oedema, inflammation, as reported in section 4 .

Safety of empty non-ionic surfactant vesicles was evaluated in vitro on HLF cells by using the trypan blue dye exclusion assay (cell mortality) and MTT viability test. Purified and unpurified empty NSVs were assayed in vitro at different surfactant concentrations (from 0.01 to $10 \mu \mathrm{M})$ and incubation-times $(24,48$ and $72 \mathrm{~h})$.

Purified non-ionic surfactant vesicles did not show a significant cytotoxic activity on HLF cells at all incubation times for concentrations ranging from 0.01 to $1 \mu \mathrm{M}$, i.e. the mortality values ranged from 1.2 to $5.81 \%$, respectively. Only at the highest investigated concentration $(10 \mu \mathrm{M})$ and after $48 \mathrm{~h}$ of incubation a slight cytotoxic effect was observed (mortality value of $16 \%)$.

It is interesting to point out that unpurified vesicles showed a significant $(\mathrm{P}<0.001)$ increase of cytotoxicity with respect to purified vesicles at all the investigated conditions (exposition times and surfactant concentrations). In this sense it was also observed that the increase of the cytotoxic effect was dependent on surfactant concentration but not on the exposition time. This finding was due to the fact that the cytotoxic action of unpurified NSVs was determined by the presence of the free molecules of surfactants, which were able to exert immediately their cytotoxic action during the incubation period by noticeably perturbing the cellular membranes (Dimitrijevic et al., 2000; Lin et al., 2007) and hence causing the cellular death. This hypothesis was strongly supported by the evidence that HLF cells treated with the free surfactants showed a greater $(\mathrm{P}<0.001)$ cytotoxic insult than those treated with unpurified non-ionic surfactant vesicles. Therefore, the assembling of surfactant into non-ionic surfactant vesicles determined a drastic reduction of cytotoxicity, due to a concomitant reduction of the free surfactant molecules in solution and/or surfactant micelles, which are able to alter the cellular permeability and homeostasis. 
Another important feature of an innovative drug delivery system is to increase the amount of active compound in the target district, thus improving the therapeutic effect of the drug. Therefore, to evaluate the delivery ability and the mechanisms of interaction of fluoresceinlabelled non-ionic surfactant vesicles with HLF cells, CLSM experiments were carried out.

Figure 9 shows how the fluorescein-labelled vesicles interacted with HLF cells at different incubation times. A green fluorescence distribution was observed in the cells just after $1 \mathrm{~h}$ incubation. After $3 \mathrm{~h}$ incubation the fluorescence of the cellular membrane and the cytoplasm became more intense and increased slightly up to $24 \mathrm{~h}$ of incubation. These findings prompted us to suppose that the main mechanism involved in the NSVs/cell interaction was the endocytosis of the carrier (Di Marzio et al., 2008), which enabled a rapid internalization in the cytoplasm. It is worthy of note that at all incubation times the localization of fluorescence was in the cytoplasm compartment and these results represent an important aspect because the glucocorticoid receptor is localized in the cytoplasm.

No fluorescence was detected in the untreated HLF cell line (control) and hence there was no interfering auto-fluorescence phenomenon (Figure 9 panel 6).

$1 \mathrm{~h}$

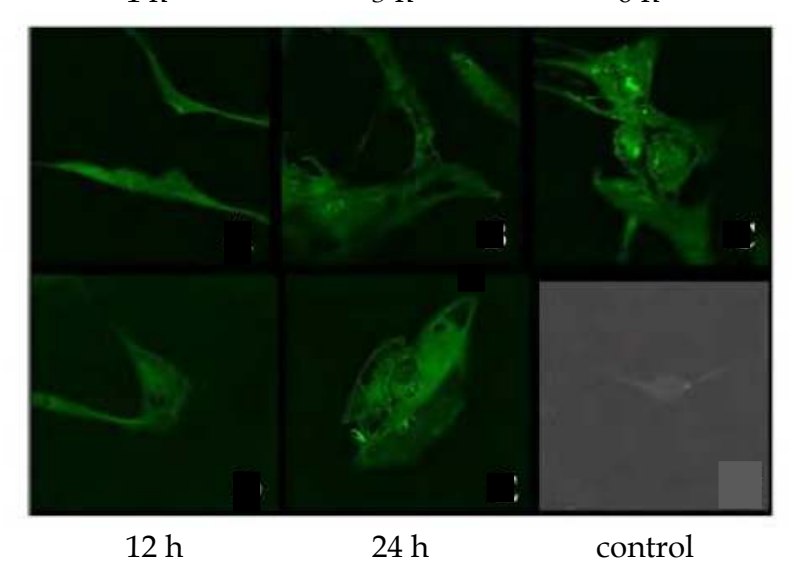

$12 \mathrm{~h}$
$3 \mathrm{~h}$

$6 \mathrm{~h}$

Fig. 9. CLSM micrographs of the interaction of fluoresceine-labelled NSVs with primary HLF cells as a function of the incubation times,. The reflectance CLSM micrographs of untreated cells were used as controls and no significant cellular fluorescence was observed

As a consequence, the improved interaction of NSVs with primary HLF cells should lead to a greater intracellular delivery of the entrapped drug.

For this reason the intracellular uptake of BDP prompted by the various formulations was investigated as a function of time (Figure 10).

Considering that surfactant molecules and unloaded non-ionic surfactant vesicles may act as drug cellular penetration enhancers and to evaluate the effective role of the vesicles in the promotion of the intracellular uptake of BDP, a mixture surfactant/BDP and a mixture empty vesicles/BDP was also assayed. As reported in Figure 10, BDP loaded non-ionic surfactant vesicles (BDP-0.4) showed a significant improvement of the intracellular uptake of the drug with respect to a mixture surfactant/BDP, a mixture empty non-ionic surfactant 




Fig. 10. HLF intracellular uptake (I.U. at $37^{\circ} \mathrm{C}$ ) of beclomethasone dipropionate (expressed as percentage of the applied dose) as a function of time by different formulations: BDP loaded NSVs (BDP-0.4), •; surfactant/BDP mixture, $\mathbf{\bullet}$; empty non-ionic surfactant vesicle/BDP mixture, $\boldsymbol{\bullet}$; free drug, $\bullet$.

vesicle/BDP and a free drug solution. This result was correlated to the ability of NSVs to easily penetrate across cell membranes of primary HLF cells (in full agreement with CSLM experiments), thus achieving a noticeable cytoplasm accumulation of BDP. These results clearly evidenced that the improvement of the drug intracellular uptake was mainly mediated by the vesicular carrier and no positive influence was exerted by the surfactant molecules and/or empty vesicles, i.e. the drug has to be entrapped within the carrier. In fact, the mixtures surfactant/drug and empty vesicle/drug showed only a slight improvement of the intracellular uptake of BDP. The profiles of BDP intracellular uptake as a function of time showed (Figure 10) a Tmax (time at which the maximum drug concentration was reached) value of $1 \mathrm{~h}$ followed by a gradual reduction of the intracellular drug accumulation up to $6 \mathrm{~h}$ in the case of the drug-loaded non-ionic surfactant vesicles. On the other side, all other tested formulations showed Tmax values of $30 \mathrm{~min}$.

The rapid internalization of BDP formulated in niosomes was not considered as a critical parameter.

The evidence of the improved intracellular entrance of NSVs and the noticeable increase of the intracellular uptake of BDP mediated by the vesicular carrier should match an improved pharmacological activity of the delivered drug. For this reason the anti-inflammatory activity of BDP-loaded non-ionic surfactant vesicles was evaluated in comparison with the free drug, as the capacity to inhibit the secretion of NGF.

NGF is an important inflammatory mediator, which contributes to the development of airway hyper-responsiveness (de Vries et al., 1999). The NGF production is stimulated by the presence of pro-inflammatory cytokines and asthma-associated cytokines, i.e. IL-1 $\beta$, and 
inhibited by anti-inflammatory glucocorticoids. Therefore, the in vitro determination of the levels of NGF secreted by HLF cells is a direct evidence of the pro- or anti-inflammatory effect of a substance.

As shown in Figure 11, the stimulation of HLF cells with IL-1 $\beta$ led to an over-secretion of NGF up to $210 \%$ of basal values (control). The treatment with the free BDP $(1 \mu \mathrm{M})$ significantly reduced both the constitutive and the IL-1 $\beta$-stimulated secretion of NGF by $18.7 \%$ and $61.23 \%$, respectively. BDP-loaded non-ionic surfactant vesicles (BDP-0.4) were much more effective than the free drug, i.e. a reduction of $68 \%$ and $85 \%$ with respect to the constitutive and IL-1 $\beta$-stimulated NGF secretion were respectively observed. These findings are in agreement with both CLSM and intracellular uptake experiments.

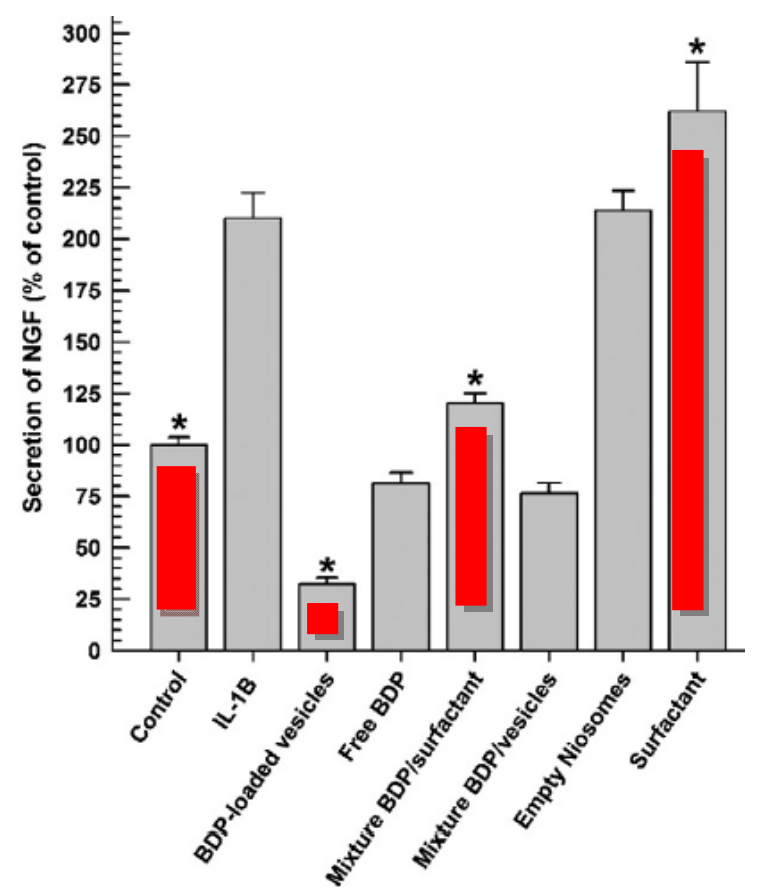

Fig. 11. Anti-inflammatory activity of various formulations containing BDP $(1 \mu \mathrm{M})$ evaluated as inhibition of NGF secretion in primary HLF cells treated with IL-1 $\beta$ (as pro-inflammatory stimulating agent). Control was untreated HLF cells, which secrete the basal level of NGF.

The use of NSV formulations was investigated not only to increase intracellular uptake of BDP in HLF cells and to improve diffusion through mucus layer but also to design an innovative system able to increase therapeutic efficacy of BDP in pulmonary diseases thus reducing the dosage and potential side effects of this drug.

\section{Conclusions}

Despite the many promising proof - of - concepts of various delivery technologies, there is still a long way ahead that must be covered. This means there are still many challenges that 
are being faced, which, in turn, mean there are still many chances for the academic and industrial scientist to make a decisive impact.

Further research efforts are needed to ensure the safety of long-term in vivo applications. There is an urgent requirement for cautiously designed toxicology and toxicokinetic studies for each nanocarrier type; the protocols should be customized for an appropriate clinical use. Furthermore, it should be pointed out that scale up from laboratory to industry is still poorly investigated in this specific area, despite its obvious importance in the ultimate goal of the development a product that can reach the market and actually give benefits to the patients.

In spite of the above reported difficulties and challenges; hopefully, within a few years, the safety and large - scale production at affordable costs of the delivery technologies described in this book will be a dream that will become true.

\section{References}

Augustí, A.G. \& Soriano, J.B. (2008). COPD as a systemic disease. COPD, Vol. 5, No. 2, (January 2008), pp. 133-138, ISSN 1541-2555.

Augustí, A.G., Noguera, A., Sauleda, J., Sala, E., Pons, J. \& Busquets, X. (2003). Systemic effects of chronic obstructive pulmonary disease. Eur Respir J, Vol. 21, No. 2, (February 2003), pp. 347-360, ISSN 0903-1936.

Altiere, R.J. \& Thompson, D.C. (1996). Pulmonary physiology and pharmacology of the airways, In: Inhalation Aerosols: Physical and Biological Basis for Therapy, Antony J. Hickey, pp. 96-99, Informa, ISBN: 0849341604, New York.

Azarmi, S., Roa , W. H. \& Löbenberg, R. (2008). Targeted delivery of nanoparticles for the treatment of lung diseases. Adv Drug Deliv Rev, Vol. 60, No. 8, (May 2008), pp. 863875, ISSN 0169-409X.

Bansil, R. \& Turner, B.S. (2006). Mucin structure, aggregation, physiological functions and biomedical applications. Curr. Opin. Colloid Interface Sci., Vol. 11, No. 2-3, (June 2006), pp. 164-170, ISSN 1359-0294.

Bansil, R., Stanley, E. \& LaMont, J.T. (1995). Mucin Biophysics. Ann Rev Physiol, Vol. 57, (March 1995), pp. 635-657, ISSN 0066-4278.

Barnes, P.J. \& Celli, B.R. (2009). Systemic manifestations and comorbidities of COPD. Eur Respir J, Vol. 33, No. 5, (May 2009), pp 1165-1185, ISSN 0903-1936.

Beckham, J.D., Cadena, A., Lin, J, Piedra, P.A., Glezen,W.P., Greenberg, S.B. \& Atmar, R.L. (2005). Respiratory viral infections in patients with chronic, obstructive pulmonary disease. J Infect, Vol. 50, No. 4, (May 2005), pp. 322-330, ISSN 0163-4453.

Bernhard, W., Haslam, P.L. \& Floros, J. (2004). From birds to humans: new concepts on airways relative to alveolar surfactant. Am J Respir Cell Mol Biol, Vol. 30, No. 1, (January 2004), pp. 6-11, ISSN 1044-1549.

Bruinenberg, P., Serisier, D., Cipolla, D. \& Blanchard, J. (2010). Safety, tolerability and pharmacokinetics of novel liposomal ciprofloxacin formulations for inhalation in healthy volunteers and non-cystic bronchiectasis patients. Am J Respir Crit Care Med, Vol. 181, B49 Meeting Abstract, (May 2010), A3192, ISSN 1073-449X. 
Bucchioni, E., Kharitonov, S.A., Allegra, L. \& Barnes, P.J. (2003). High levels of interleukin-6 in the exhaled breath condensate of patients with COPD. Respir Med, Vol. 97, No. 12, (December 2003), pp. 1299-1302, ISSN 0020-1324.

Buhling, F., Groneberg, D. \& Welte, T. (2006). Proteases and their role in chronic inflammatory lung diseases. Curr Drug Targets, Vol. 7, No. 6, (June 2006), pp. 751759, ISSN 1389-4501.

Buhling, F., Waldburg, N., Reisenauer, A., Heimburg, A., Golpon, H. \& Welte, T. (2004). Lysosomal cysteine proteases in the lung: role in protein processing and immunoregulation. Eur Respir J, Vol. 23, No. 4, (April 2004), pp. 620-628, ISSN 0903-1936.

Byrne, J.D. \& Baugh, J.A. (2008), The significance of nanoparticles in particle-induced pulmonary fibrosis. Mcgill J Med, Vol. 11, No. 1, (January 2008), pp. 43-50, ISSN 1201-026X.

Carafa, M., Marianecci, C., Lucania, G., Marchei, E. \& Santucci, E. (2004). New vesicular ampicillin-loaded delivery systems for topical application : characterization, in vitro permeation experiments and antimicrobial activity. J Control Release, Vol. 95, No. 1, (February 2004), pp. 67-74, ISSN 0168-3659.

Carafa, M., Santucci, E. \& Lucania, G. (2002). Lidocaine-loaded non-ionic surfactant vesicles: characterization and in vitro permeation studies, Int J Pharm, Vol. 231, No. 1, (January 2002), pp. 221-232, ISSN 0378-5173.

Caramori, G., Di Gregorio, C., Carlstedt, I., Casolari, P., Guzzinati, I. \& Adcock, I.M. (2004). Mucin expression in peripheral airways of patients with chronic obstructive pulmonary disease. Histopathology, Vol. 45, No. 5, (November 2004), pp. 477-484, ISSN 1365-2559.

Cefalu, WT. (2004). Concept, strategies, and feasibility of noninvasive insulin delivery. Diabetes Care, Vol. 27, No. 1, (January 2004), pp. 239-46, ISSN 0149-5992.

Celia, C., Trapasso, E., Cosco, D., Paolino., D. \& Fresta, M. (2009). Turbiscan Lab® Expert analysis of the stability of ethosomes ${ }^{\circledR}$ and ultradeformable liposomes containing a bilayer fluidizing agent. Colloids Surf. B Biointerface, Vol. 72, No. 1, (August 2009), pp. 155-160 ISSN 0927-7765.

Celli, B.R. \& MacNee, W. (2004). Standards for the diagnosis and treatment of patients with COPD: A summary of the ATS/ ERS position paper. Eur Respir J, Vol.23, No. 6, (June 2004), pp. 932-946, ISSN 0903-1936.

Clunes, M.T. \& Boucher, R.C. (2007). Cystic fibrosis: the mechanisms of pathogenesis of an inherited lung disorder. Drug Discov Today Dis Mech, Vol. 4, No. 2, (June 2007), pp. 63-72, ISSN 1740-6765.

Cosco, D., Paolino, D., Muzzalupo, R., Celia, C., Citraro, R., Caponio, D., Picci, N. \& Fresta, M. (2009) Novel PEG-coated niosomes based on bola-surfactant as drug carriers for 5-fluorouracil. Biomed. Microdevices, Vol. 11, No. 5 ,(October 2009), pp. 1115-1125, ISSN 1387-2176.

Crapo, J.D., Barry, B.E., Gehr, P., Bachofen, M. \& Weibel, E.R. (1982). Cell number and cell characteristics of the normal human lung. Am Rev Respir Dis, Vol. 126, No. 3, (August 1982), pp. 332-337, ISSN 0003-0805.

Dailey, L.A., Schmehl, T., Gessler, T., Wittmar, M., Grimminger, F., Seeger, W., \& Kissel, T. (2003). Nebulization of biodegradable nanoparticles: impact of nebulizer 
technology and nanoparticle characteristics on aerosol features. J Control Release, Vol. 86, No. 1, (January 2003), pp.131-44, ISSN: 0168-3659.

Darwis, Y. \& Kellaway, I.W. (2001). Nebulization of rehydrated freeze-dried beclomethasone dipropionate liposomes. Int J Pharm, Vol. 215, No. 1-2, (March 2001), pp. 113-121. ISSN 0378-5173.

Daviskas, E., Anderson, S.D., Shaw, J., Eberl, S., Seale, J.P., Yang, I.A. \& Young, I.H. (2005). Mucociliary clearance in patients with chronic asthma: effects of beta agonists. Respirology, Vol. 10, No. 4, (September 2005), pp. 426-435, ISSN: 1440-1843.

de Vries, A., Dessing, M.C., Engels, F., Henricks, P.A.J. \& Nijkamp, F.P. (1999). Nerve growth factor induces a neurokinin-1 receptor-mediated airway hyperresponsiveness in guinea pigs. Am J Respir Crit Care Med, Vol. 159, No. 5, (May 1999), pp. 1541-1544, ISSN 1073-449X.

Decramer, M. \& Janssens, J. (2010). Mucoactive therapy in COPD. Eur Respir Rev, Vol. 19, No. 116, (June 2010), 134-140, ISSN 0905-9180.

Dekhuijzen, P.N. (2004). Antioxidant properties of N-acetylcysteine: their relevance in relation to chronic obstructive pulmonary disease. Eur Respir J, Vol. 23, No. 4, (April 2004), pp. 629-636, ISSN 0903-1936.

Desai, T.R. \& Finlay, W.H. (2002). Nebulization of niosomal all-trans-retinoic acid : an inexpensive alternative to conventional liposomes. Int J Pharm, Vol. 241, No. 2 (July 2002), pp. 311-317, ISSN 0378-5173.

Deshmukh, H. S., Shaver, C., Case, L.M., Dietsch, M., Wesselkamper, S. C. \& Hardie,W. D. (2008). Acrolein-activated matrix metalloproteinase 9 contributes to persistent mucin production. Am J Respir Cell Mol Biol, Vol. 38, No. 4, (April 2008), pp. 446-454, ISSN 1044-1549.

Di Marzio, L., Marianecci, C., Cinque, B., Nazzarri, M., Cimini, A.M., Cristiano., L., Cifone, M.G., Alhaique, F. \& Carafa, M. (2008). pH-sensitive non-phospholipid vesicle and macrophage-like cells: binding, uptake and endocytotic pathway. Biochim Biophys Acta, Vol. 1778, No. 12, (December 2008), pp. 2749-2756 ISSN 0005-2736.

Dimitrijevic, D., Shaw, A.J. \& Florence, A.T. (2000). Effects of some non-ionic surfactants on transepithelial permeability in Caco-2 cells. J Pharm Pharmacol, Vol. 52, No. 2, (February 2000), pp. 157-162 ISSN 0022-3573

Dumont, J.A., Bitonti, A.J., Clark, D., Evans, S., Pickford, M. \& Newman, S.P. (2005). Delivery of an erythropoietin-Fc fusion protein by inhalation in humans through an immunoglobulin transport pathway. J Aerosol Med, Vol. 18, No. 3, (September 2005), pp. 294-303, ISSN 0894-2684.

Edsbäcker, S, Wollmer, P., Selroos, O., Borgstroem, L., Olsson, B. \& Ingelf J. (2008). Do airway clearance mechanisms influence the local and systemic effects of inhaled corticosteroids? Pulm Pharmacol Ther, Vol. 21, No. 2, (April 2008), pp. 247-258, ISSN 1094-553.

El-Chemaly, S., Pacheco-Rodriguez, G., Ikeda, Y., Malide, D. \& Moss, J. (2009). Lymphatics in idiopathic pulmonary fibrosis: new insights into an old disease. Lymphat Res Biol, Vol. 7, No. 4, (December 2009),pp. 197-203, ISSN 1539-6851

Evans, C.M. \& Koo, J.S. (2009). Airway mucus: the good, the bad, the sticky. Pharmacol Ther, Vol. 121, No. 3, (March 2009), pp. 332-348, ISSN 0163-7258.

Furuyama, A., Kanno., S., Kobayashi, T. \& Hirano., S. (2009). Extrapulmonary translocation of intratracheally instilled fine and ultrafine particles via direct and alveolar 
macrophage-associated routes. Arch Toxicol, Vol. 83, No. 5, (May 2009), pp. 429-437, ISSN 0340-5761.

Gan, W.Q., Man, S.F., Senthilselvan, A. \& Sin, D.D. (2004). Association between chronic obstructive pulmonary disease and systemic inflammation: a systematic review and a meta-analysis. Thorax, Vol. 59, No. 6, (June 2004) pp. 574-580, ISSN 1468-3296.

Geiser M. \& Kreyling, W.G. (2010). Deposition and biokinetics of inhaled naNo.particles. Part. Fibre Toxicol, Vol. 7, No. 2, (January 2010), pp. 1-17, ISSN 1743-8977.

Geiser, M. (2010). Update on macrophage clearance of inhaled micro- and nanoparticles. J Aerosol Med Pulm Drug Deliv, Vol. 23, No. 4, (August 2010), pp. 207-17, ISSN 19412711.

Geiser, M., Casaulta, M., Kupferschmid, B., Schulz, H., Semmler-Behnke, M. \& Kreyling, W. (2008). The role of macrophages in the clearance of inhaled ultrafine titanium dioxide particles. Am J Respir Cell Mol Biol, Vol. 38, No. 3, (March 2008), pp. 371376, ISSN: 1044-1549.

Gonda, I. (2006). Systemic delivery of drugs to humans via inhalation. J Aerosol Med, Vol. 19, No. 1, (March 2006), pp. 47-53, ISSN 0894-2684.

Griesenbach, U. \& Alton, E.W. (2009). Gene transfer to the lung: lessons learned from more than 2 decades of CF gene therapy. Adv Drug Deliv Rev, Vol. 61, No. 2, (February 2009), pp. 128-139, ISSN 0169-409X.

Haley, B. \& Frenkel, E. (2008). Nanoparticles for drug delivery in cancer treatment. Urol Oncol, Vol. 26, No. 1, (January-February 2008), pp. 57-64, ISSN 1078-1439.

Heyder, J., Gebhart, J., Rudolf, G., Schiller, C.F. \& Stahlhofen, W. (1985). Deposition of particles in the human respiratory tract in the size range $0.005-15 \mu \mathrm{m}$. J Aerosol Sci, Vol. 17, No. 5, (May 1985), pp. 811-25, ISSN 0021-8502.

Hinds, W.C. (1999). Uniform Particle Motion. In: Aerosol Technology: Properties, Behavior and Measurement of Airborne Particles Second ed., William C. Hinds, pp. 53-55, Wiley, ISBN 978-0-471-19410-1, New York.

Hogg, J. C., Chu, F., Utokaparch, S., Woods, R., Elliott, W. M. \& Buzatu, L. (2004). The nature of small-airway obstruction in chronic obstructive pulmonary disease. $N$ Engl J Med, Vol. 350, No. 26, (June 2004), pp. 2645-2653, ISSN 0028-4793.

Hogg, J.C., Chu, F.S. \& Tan, W.C. (2007). Survival after lung volume reduction in chronic obstructive pulmonary disease: insights from small airway pathology. Am J Respir Crit Care Med, Vol. 176, No. 4, (August 2007), pp. 454-459, ISSN 1044-1549.

Holt, P.G., Strickland, D.H., Wikstrom, M.E. \& Jahnsen, F.L. (2008). Regulation of immunological homeostasis in the respiratory tract. Nat Rev Immunol, Vol. 8, No. 2, (February 2008), pp. 142-52, ISSN 1474-1733.

Huang, C.C., Aronstam, R.S., Chen, D.R. \& Huang, Y.W. (2010). Oxidative stress, calcium homeostasis, and altered gene expression in human lung epithelial cells exposed to ZnO nanoparticles. Toxicol In Vitro, Vol. 24, No. 1, (February 2010), pp. 45-55, ISSN 0887-2333.

Huertas, A. \& Palange, P. (2011). COPD: a multifactorial systemic disease. Ther Adv Respir Dis, Vol. 5, No. 3, (March 2011), pp. 217-224, ISSN 1753-4658.

Illum L. (2002). Nasal drug delivery: new developments and strategies. Drug Discov Today, Vol. 7, No. 23, (December 2002), pp. 1184-1189, ISSN 1359-6446. 
Ishitsuka, T, Akita, H. \& Harashima, H. (2011). Functional improvement of an IRQ-PEGMEND for delivering genes to the lung. J Control Release, Vol. 154, No. 1, pp. 77-83, ISSN 0168-3659.

Kim, V, Criner, G.J., Abdallah, H.Y., Gaughan, J.P., Furukawa, S. \& Solomides, C.C. (2005). Small airway morphometry and improvement in pulmonary function afterlung volume reduction surgery. Am J Respir Crit Care Med, Vol. 171, No. 1, (January 2005), pp. 40-47, ISSN 1044-1549.

Klaine, S.J., Alvarez, P.J.J., Batley, G.E., Fernandes, T.F. \& Handy, R.D. (2008). Nanomaterials in the environment: Behavior, fate, bioavailability, and effects. Environ Toxicol Chem, Vol. 27, No. 9, (September 2008), pp. 1825-1851, ISSN 0730-7268.

Kurmi, B.D., Kayat, J., Gajbhiye, V., Tekade, R.K. \& Jain, N.K. (2010). Micro- and nanocarrier-mediated lung targeting. Expert Opin Drug Deliv, Vol. 7, No. 7, (July 2010), pp. 781-794, ISSN 1742-5247.

Lai, S.K., Wang, Y.Y. \& Hanes, J. (2009). Mucus-penetrating nanoparticles for drug and gene delivery to mucosal tissues. Adv Drug Deliv Rev, Vol. 61, No. 2, (February 2009), pp. 158-171, ISSN 0169-409X.

Lam, J.K., Liang, W. \& Chan, H.K. (2011). Pulmonary delivery of therapeutic siRNA. Adv Drug Deliv Rev, Article in Press, ISSN 0169-409X.

Li, P., Liu, D., Sun, X., Liu, C., Liu, Y. \& Zhang, N. (2011). A novel cationic liposome formulation for efficient gene delivery via a pulmonary route. Nanotechnology, Vol. 22, No. 24, (June 2011), art. No. 245104 (11 pages), ISSN 1361-6528.

Lin, H., Gebhardt, M., Bian, S., Kwon, K.A., Shim, C.K., Chung, S.J. \& Kim D.D (2007). Enhancing effect of surfactants on fexofenadine $\mathrm{HCl}$ transport across the human nasal epithelial cell monolayer, Int J Pharm, Vol. 330, No. 1-2, (February 2007), pp. 23-31, ISSN 0378-5173.

Lkhasuren, O., Takahashi, K. \& Dash-Onolt, L (2007). Occupational lung diseases and the mining industry in Mongolia. Int J Occup Environ Health, Vol. 13, No. 2, (April 2007), pp. 195-201, ISSN 1077-3525.

Lodge, T.P. (1999). Reconciliation of the molecular weight dependence of diffusion and viscosity in entangled polymers. Phys Rev Lett, Vol. 83, No. 16, (October 1999), pp. 3218-3221, ISSN 0031-9007.

Madl, A.K. \& Pinkerton, K.E. (2009). Health effects of inhaled engineered and incidental nanoparticles. Crit Rev Toxicol, Vol. 39, No. 8, (September 2009), pp. 629-658, ISSN $1040-8444$.

Mall, M., Grubb, B.R., Harkema, J.R., O’Neal, W.K. \& Boucher, R.C. (2004). Increased airway epithelial $\mathrm{Na}+$ absorption produces cystic fibrosis-like lung disease in mice. Nat Med, Vol. 10, No. 4, (April 2004), pp. 487-493, ISSN 1078-8956.

Mannino, D.M., Homa, D.M., Akinbami, L.J., Ford, E.S., \& Redd, S.C. (2002). Chronic obstructive pulmonary disease surveillance-United States, 1971-2000. Respir Care, Vol. 47, No. 10, (October 2002), pp.1184-1199, ISSN 0020-1324.

Mansour, H.M., Rhee, Y.S. \& Wu, X. (2009). Nanomedicine in pulmonary delivery. Int J Nanomedicine, Vol. 4, (December 2009), pp. 299-319, ISSN 1176-9114.

Meers, P., Neville, M., Malinin, V., Scotto, A.W., Sardaryan, G., Kurumunda, Mackinson, R., James, G., Fisher, S. \& Perkins, W.R. (2008). Biofilm penetration, triggered release and in vivo activity of inhaled liposomal amikacin in chronic Pseudomonas 
aeruginosa lung infections. J Antimicrob Chemother, Vol. 61, No. 4, (April 2008), pp. 859-868, ISSN 0305-7453.

Mercer, R.R., Russell, M.L., Roggli, V.L. \& Crapo, J.D. (1994). Cell number and distribution in human and rat airways. Am J Respir Cell Mol Biol, Vol. 10, No. 6, (June 1994), pp. 613-624, ISSN 1044-1549.

Misra, A., Jinturkar, K., Patel, D., Lalani, J. \& Chougule, M. (2009). Recent advances in liposomal dry powder formulations: preparation and evaluation. Expert Opin Drug Deliv, Vol. 6, No. 1, (January 2009), pp. 71-89, ISSN 1742-5247.

Mitsopoulos, P. \& Suntres, Z. E (2011). Protective effects of liposomal N-acetylcysteine against paraquat-induced cytotoxicity and gene expression. J Toxicol, Vol. 2011, Article ID 808967 (14 pages), ISSN 1687-8205.

Montenegro, L., Panico, A.M. \& Bonina, F. (1996). Quantitative determination of hydrophobic compound entrapment in DPPC liposomes by DSC. Int J Pharm, Vol. 138, No. 2, (July 1996), pp.191-197, ISSN 0378-5173.

Morawska, L., Hofmann, W., Hitchins-Loveday, J., Swanson, C. \& Mengersen, K. (2005). Experimental study of the deposition of combustion aerosols in the human respiratory tract. J Aerosol Sci, Vol. 36, No. 8, (August 2005), pp. 939-957, ISSN 00218502.

Muhlfeld, C., Gehr, P. \& Rothen-Rutishauser, B. (2008). Translocation and cellular entering mechanisms of nanoparticles in the respiratory tract. Swiss Med Wkly, Vol. 138, No. 27-28, (July 2008), pp. 387-391, ISSN 1424-7860.

Muhlfeld, C., Rothen-Rutishauser, B., Blank, F., Vanhecke, D., Ochs, M. \& Gehr, P. (2008). Interactions of nanoparticles with pulmonary structures and cellular responses. Am J Physiol Lung Cell Mol Physiol, Vol. 294, No. 5, (May 2008), pp. 817-829, ISSN 10400605.

Neumiller, J.J. \& Campbell, R.K. (2010). Technosphere insulin: an inhaled prandial insulin product. BioDrugs, Vol. 24, No. 3, (June 2010), pp. 165-172, ISSN 1173-8804.

Nguyen, J., Reul, R., Betz, T., Dayyoub, E., Schmehl, T., Gessler, T., Bakowsky, U., Seeger, W. \& Kissel, T. (2009). Nanocomposites of lung surfactant and biodegradable cationic nanoparticles improve transfection efficiency to lung cells. J Control Release, Vol. 140, No. 1, (November 2009), pp. 47-54, ISSN 0168-3659.

Nimje, N., Agarwal, A., Saraogi, G.K., Lariya, N., Rai, G., Agrawal, H. \& Agrawai, G.P. (2009). Mannosylated nanoparticulate carriers of rifabutin for alveolar targeting. J Drug Target, Vol. 17, No. 10, (December 2009), pp. 777-787, ISSN 1061-186X.

Oakley, R.H., Jewell, C.M., Yudt, M.R., Bofetiado, D.M. \& Cidlowski, J.A. (1999). The dominant negative activity of the human glucocorticoid receptor beta isoform. Specificity and mechanisms of action. J Biol Chem, Vol. 274, No. 3, (Septmber 1999), pp. 27857-27866, ISSN 0021-9258.

Oberdörster, G. (2007). Biokinetics and effects of nanoparticles, In: Nanotechnology Toxicological Issues and environmental safety, P.P. Simeonova, N. Opopol, M.I. Luster, pp. 15-51, Springer, ISBN 978-1-4020-6074-8, Netherlands.

Oberdorster, G., Oberdorster, E. \& Oberdorster, J. (2005). Nanotoxicology: an emerging discipline evolving from studies of ultrafine particles. Environ Health Persp, Vol. 113, No. 7, (July 2005), pp. 823-839, ISSN 0091-6765.

Oberdorster, G., Stone, V. \& Donaldson K. (2007). Toxicology of nanoparticles: a historical perspective. Nanotoxicology, Vol. 1, No. 1, (January 2007), pp. 2-25, ISSN 1743-5390. 
Okusanya, O.O., Bhavnani, S.M., Hammel, J., Minic, P., Dupont, L.J., Forrest, A., Mulder, G.J, Mackinson, C., Ambrose, P.G., Gupta, R. (2009). Pharmacokinetic and pharmacodynamic evaluation of liposomal amikacin for inhalation in cystic fibrosis patients with chronic pseudomonal infection. Antimicrob Agents Chemother, Vol. 53, No. 9, (September 2009), pp. 3847-3854, ISSN 0066-4804.

Palange, P., Testa, U., Huertas, A., Calabro', L., Antonucci, R. \& Petrucci, E. (2006). Circulating haemopoietic and endothelial progenitor cells are decreased in COPD. Eur Respir J. Vol. 27, No. 3 (March 2006), pp. 529-541, ISSN 0903-1936.

Palko, H.A., Fung, J.Y. \& Louie, A.Y. (2010). Positron emission tomography: a novel technique for investigating the biodistribution and transport of nanoparticles. Inhal Toxicol, Vol. 22, No. 8, (July 2010), pp. 657-688, ISSN 0895-8378.

Paolino, D., Cosco, D., Muzzalupo, R., Trapasso, E., Picci, N. \& Fresta, M. (2008). Innovative bolasurfactant niosomes as topical delivery systems of 5-fluorouracil for the treatment of skin cancer. Int J Pharm, Vol. 353, No. 1-2, (April 2008), pp. 233-242, ISSN 0378-5173.

Paolino, D., Muzzalupo, R., Ricciardi, A., Celia, C., Picci, N. \& Fresta, M. (2007). In vitro and in vivo evaluation of Bola-surfactant containing niosomes for transdermal delivery. Biomed. Microdevices, Vol. 9, No. 4 (August 2007), pp. 421-433, ISSN 1387-2176.

Parkes, W.R. (1994). Morphology of the respiratory tract, In: Occupational lung disorders, Butterworth-Heinemann, pp. 1-17, Butterworth-Heinemann Medical, ISBN 075061403X, Oxford, UK.

Patton, J.S. \& Byron, P.R. (2007). Inhaling medicines: delivering drugs to the body through the lungs. Nat Rev Drug Discov, Vol. 6, No. 1, (January 2007), pp. 67 - 74, ISSN 1474-1776.

Perez-Gil, J. (2008). Structure of pulmonary surfactant membranes and films: the role of proteins and lipid-protein interactions. BBA, Vol. 1778, No. 7-8, (July-August 2008), pp. 1676-1695, ISSN 0005-2736.

Quinton, P.M. (2008). Cystic fibrosis: impaired bicarbonate secretion and mucoviscidosis. Lancet, Vol. 372, No. 9636 (August 2008), pp. 415-417, ISSN 0140-6736.

Rahman, I \& Kilty, I. (2006). Antioxidant therapeutic targets in COPD. Curr Drug Targets, Vol. 7, No. 6 (June 2006), pp. 707-720, ISSN 1389-4501.

Rahman, I., Skwarska, E. \& MacNee, W. (1997). Attenuation of oxidant/antioxidant imbalance during treatment of exacerbations of chronic obstructive pulmonary disease. Thorax, Vol. 52, No. 6, (June 1997), pp. 565-568, ISSN 1468-3296.

Randell, S.H. \& Boucher, R.C. (2006). Effective mucus clearance is essential for respiratory health. Am J Respir Cell Mol Biol, Vol. 35, No. 1, (July 2006), pp. 20-28, ISSN 10441549.

Remels, A.H., Gosker, H.R., van der Velden, J., Langen, R.C. \& Schols, A.M. (2007). Systemic inflammation and skeletal muscle dysfunction in chronic obstructive pulmonary disease: State of the art and novel insights in regulation of muscle plasticity. Clin Chest Med, Vol. 28, No. 3, (September 2007), pp. 537-552, ISSN 0272-5231.

Robinson, M., Eberl, S., Tomlinson, C., Daviskas, E., Regnis, J.A., Bailey, D.L., Torzillo, P.J., Menache, M. \& Bye, P.T. (2000). Regional mucociliary clearance in patients with cystic fibrosis. J. Aerosol Med., Vol. 13, No. 2, (June 2000), pp. 73-86, ISSN 0894-2684.

Rogers, D.F. \& Barnes, P.J. (2006). Treatment of airway mucus hypersecretion. Ann Med, Vol. 38, No. 2, (January 2006), pp.116-125, ISSN 0785-3890. 
Rogers, D.F. (2007). Physiology of airway mucus secretion and pathophysiology of hypersecretion. Respir Care, Vol. 52, No. 9, (September 2007), pp. 1134-1146, ISSN 0020-1324.

Rossiter, A., Howard, C.P., Amin, N., Costello, D.J. \& Boss A.H. (2010). Technosphere ${ }^{\circledR}$ Insulin: Safety in Type 2 Diabetes Mellitus. ADA Scientific Sessions, Orlando Florida, June 2010.

Santucci, E., Carafa, M., Coviello, T., Murtas, E., Riccieri, F.M., Alhaique, F., Modesti, A. \& Modica, A. (1996). Vesicles from polysorbate 20 and cholesterol. A simple preparation and a characterization. STP Pharma Sci, Vol. 6, No. 1, (January 1996), pp. 29-32, ISSN 1157-1489.

Schmid, O., Moller, W., Semmler-Behnke, M., Ferron, G.A., Karg, E., Lipka, J., Schulz, H., Kreyling, W.G. \& Stoeger, T. (2009). Dosimetry and toxicology of inhaled ultrafine particles. Biomarkers, Vol. 14, No. 1, (July 2009), pp. 67-73, ISSN 1354-750X.

Schmidt, S.R. (2009). Fusion-proteins as biopharmaceuticals-applications and challenges. Curr Opin Drug Discov Dev, Vol. 12, No. 2, (March 2009), pp. 284-295, ISSN 13676733.

Shao, M.X., Nakanaga, T. \& Nadel, J.A. (2004). Cigarette smoke induces MUC5AC mucin overproduction via tumor necrosis factor-alpha-converting enzyme in human airway epithelial (NCI-H292) cells. Am J Physiol Lung Cell Mol Physiol, Vol. 287, No. 2, (August 2004), pp. 420-427, ISSN 1040-0605.

Sin, D.D. \& Man, S.F. (2003). Why are patients with chronic obstructive pulmonary disease at increased risk of cardiovascular diseases? The potential role of systemic inflammation in chronic obstructive pulmonary disease. Circulation, Vol. 107, No. 6, (June 2003), pp. 1514-1519, ISSN 0009-7322.

Stamenkovic, I. (2003). Extracellular matrix remodelling: the role of matrix metalloproteinases. J Pathol, Vol. 200, No. 4, (July 2003), pp. 448-464, ISSN 10969896.

Sung, J.C., Pulliam, B.L. \& Edwards, D.A. (2007). Nanoparticles for drug delivery to the lungs. Trends Biotechnol, Vol. 25, No. 12, (December 2007), pp. 563-570, ISSN 01677799 .

Tetley,T.D. (2002). Macrophages and the pathogenesis of COPD. Chest, Vol. 121, No. 1, (January 2002), pp. 156S-159S, ISSN 0012-3692.

Tsapis, N., Bennett, D., Jackson, B., Weitz, D.A. \& Edwards, D.A. (2002). Trojan particles: large porous carriers of nanoparticles for drug delivery. Proc Natl Acad Sci, Vol. 99, No. 19, (September 2002), pp. 12001-12005, ISSN 0027-8424.

Unfried, K., Albrecht, C., Klotz, L.O., Von Mikecz, A., Grether-Beck, S., Schins, R.P.F. (2007). Cellular responses to nanoparticles: target structures and mechanisms. Nanotoxicology, Vol. 1, No. 1, (January 2007), pp. 51-71, ISSN 1743-5390.

Van der Schans, C.P. (2007). Bronchial mucus transport. Respir Care, Vol. 52, No. 9, (September 2007), pp. 1150-1156, ISSN 0020-1324.

van der Velden, V. \& Hulsmann, A.R. (1999). Peptidases: structure, function and modulation of peptide-mediated effects in the human lung. Clin Exp Allergy, Vol. 29, No. 4, (April 1999), pp. 445-456, ISSN 1365-2222.

Verdugo, P. (1990). Goblet cells secretion and mucogenesis. Ann Rev Physiol, Vol. 52 (March 1990), pp.157-176, ISSN 0066-4278. 
Veronese, F.M. \& Pasut, G. (2005). PEGylation, successful approach to drug delivery. Drug Discov Today, Vol. 10, No. 21, (November 2005), pp. 1451-1458, ISSN 1359-6446.

Walvoord E.C., de la PAZ, Park, S., Silverman, B., Cuttler,L., Rose, S.R. (2009). Inhaled growth hormone $(\mathrm{GH})$ compared with subcutaneous $\mathrm{GH}$ in children with $\mathrm{GH}$ deficiency: pharmacokinetics, pharmacodynamics, and safety. J Clin Endocrinol Metab, Vol. 94, No. 6, (March 2009), pp. 2052-2059, ISSN 0021-972X.

Wedzicha, J.A. \& Donaldson, G.C. (2003). Exacerbations of chronic obstructive pulmonary disease. Respir Care, Vol. 48, No. 12, (December 2003), pp. 1204-1213, ISSN 00201324.

Weers, J., Metzheiser, B., Taylor, G., Warren, S., Meers, P. \& Perkins, W.R. (2009). A gamma scintigraphy study to investigate lung deposition and clearance of inhaled amikacin-loaded liposomes in healthy male volunteers. J Aerosol Med Pulm Drug Deliv, Vol. 22, No. 2, (June 2009), pp. 131-138, ISSN 1941-2711.

Wouters, E.F. (2002). Systemic effects in COPD. Chest, Vol.121, No. 1, (January 2002), pp. 127S-130S, ISSN 0012-3692.

Xia, T., Li, N. \& Nel, A.E. (2009). Potential health impact of nanoparticles. Annu Rev Public Health, Vol. 30, (April 2009), pp. 137-150, ISSN 0163-7525.

Yang W., Peters, J.I. \& Williams, R.O. (2008). Inhaled nanoparticles - a current review. Int. J. Pharm, Vol. 356, No. 1-2, (May 2008), pp. 239-247, ISSN 0378-5173.

Yuan, X., Naguib, S., Yuan, X., Naguib, S. \& Wu, Z (2011). Recent advances of siRNA delivery by nanoparticles. Expert Opin Drug Deliv, Vol. 8, No. 4, (April 2001), pp. 521-536, ISSN 1742-5247.

Zhang, J., Wu, L., Chan, H. \& Watanabe, W. (2011). Formation, characterization, and fate of inhaled drug nanoparticles. Adv Drug Deliv Rev, Vol. 63, No.6, (May 2011), pp. 441455, ISSN 0169-409X. 


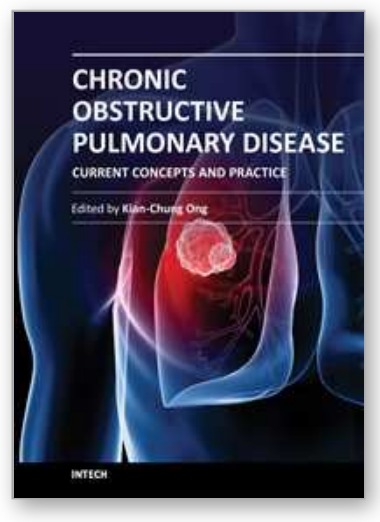

\author{
Chronic Obstructive Pulmonary Disease - Current Concepts and \\ Practice \\ Edited by Dr. Kian-Chung Ong
}

ISBN 978-953-51-0163-5

Hard cover, 474 pages

Publisher InTech

Published online 02, March, 2012

Published in print edition March, 2012

A decade or so ago, many clinicians were described as having an unnecessarily 'nihilistic' view of COPD. This has certainly changed over the years... This open access book on COPD provides a platform for scientists and clinicians from around the world to present their knowledge of the disease and up-to-date scientific findings, and avails the reader to a multitude of topics: from recent discoveries in the basic sciences to state-of-the-art interventions on COPD. Management of patients with COPD challenges the whole gamut of Respiratory Medicine - necessarily pushing frontiers in pulmonary function (and exercise) testing, radiologic imaging, pharmaceuticals, chest physiotherapy, intensive care with respiratory therapy, bronchology and thoracic surgery. In addition, multi-disciplinary inputs from other specialty fields such as cardiology, neuro-psychiatry, geriatric medicine and palliative care are often necessary for the comprehensive management of COPD. The recent progress and a multi-disciplinary approach in dealing with COPD certainly bode well for the future. Nonetheless, the final goal and ultimate outcome is in improving the health status and survival of patients with COPD.

\title{
How to reference
}

In order to correctly reference this scholarly work, feel free to copy and paste the following:

Maria Carafa, Carlotta Marianecci, Paolino Donatella, Luisa Di Marzio, Christian Celia, Massimo Fresta and Franco Alhaique (2012). Novel Concept in Pulmonary Delivery, Chronic Obstructive Pulmonary Disease Current Concepts and Practice, Dr. Kian-Chung Ong (Ed.), ISBN: 978-953-51-0163-5, InTech, Available from: http://www.intechopen.com/books/chronic-obstructive-pulmonary-disease-current-concepts-andpractice/novel-concept-in-pulmonary-delivery

\section{INTECH}

open science | open minds

\section{InTech Europe}

University Campus STeP Ri

Slavka Krautzeka 83/A

51000 Rijeka, Croatia

Phone: +385 (51) 770447

Fax: +385 (51) 686166

www.intechopen.com

\section{InTech China}

Unit 405, Office Block, Hotel Equatorial Shanghai

No.65, Yan An Road (West), Shanghai, 200040, China 中国上海市延安西路65号上海国际贵都大饭店办公楼 405 单元

Phone: +86-21-62489820

Fax: $+86-21-62489821$ 
(C) 2012 The Author(s). Licensee IntechOpen. This is an open access article distributed under the terms of the Creative Commons Attribution 3.0 License, which permits unrestricted use, distribution, and reproduction in any medium, provided the original work is properly cited. 